\title{
La «Peste des Petits Ruminants » en Afrique occidentale française ses rapports avec la Peste Bovine
}

\author{
P. MORNET Par J. ORUE \\ Y. GILBERT G. THIERY \\ et SOW MAMADOU
}

Contrairement à l'usage, nous présentons d'abord une étude d'ensemble de la maladie, sous une forme didactique. Ensuite, nous décrivons l'étude expérimentale. Cette synthèse préalable facilite la compréhension des nombreux essais effectués.

Au cours de nos recherches, bien souvent interrompues par d'autres travaux variés et absorbants, nous avons reçu le meilleur accueil des chefs de service de la Côte-d'Ivoire et de la Guinée.

Nous tenons à romercicr spćcialement M. A. Larde, chef du Service de l'Élevage de la Guinće, qui, grâce à une organisation remarquable et une très amicale collaboration, nous a permis de mener à bien nos dernières expériences. Le personnel qu'il a mis à notre disposition, et en particulier $\mathrm{M}$. Sow Mamadou, vétérinaire africain, a été d'une très grande efficacité.

\section{Historique - Dénominations}

D'après Gargadennec et Lalanne (1942), cette affection aurait été observée par eux pour la première fois en Moyenne Côte-d'Ivoire, au cours du deuxième trimestre 1940, sur les ovins et les caprins, causant des pertes considérables principa-lement chez les caprins.

Ils assimilent cette maladie tout d'abord à la bluetongue (1940), puis à la stomatite ulcéreuse (1941). En 1942, ils la dénomment enfin " Peste des petits ruminants " par suite des analogies cliniques avec la peste bovine.

Au Dahomey, en 1941, Cathou signale une entité morbide identique qu'il appelle "Peste des espèces ovine et caprine ». Il adopte, l'année suivante, la même dénomination que Gargadennec et Lalanne.

Parmi les huit territoires de l'A.O.F., seuls la Côted'Ivoire et le Dahomey signalent régulièrement chaque année des foyers de cette maladie.

Au début de l'année 1955, l'achat de moutons en Casamance et de chèvres dans la région de Kaolack (Sénégal) nous a donné l'occasion d'avoir un tableau clinique complet de l'affection, sous ses diverses formes.
Enfin, au cours du premier trimestre 1956, Sar Samba Cor, dans cette même région dẹ Kaolack, rencontre plusieurs foyers dont les répercussions commencent à émouvoir les éleveurs.

\section{Espèces affectées}

Les ovins et les caprins sont seuls atteints dans la maladie naturelle et ces derniers, beaucoup plus fréquemment que les premiers, plus résistants.

Les jeunes animaux, de six à dix-huit mois, sont plus réceptifs que les adultes; par contre, le sexe n'a pas d'influence.

Les bovins vivant au contact des malades n'extériorisent pas de signes cliniques décelables.

\section{Répartition géographique Importance de la maladie}

Si la maladie est plus fréquemment déleclée en certaines régions : Cercles de Parakou et Savalou au Dahomey, Cercles de Daloa en Côte-d'Ivoire, ces deux Territoires sont cependant entièrement infectés.

Il est probable que des enquêtes plus poussées permettront de mettre en évidence la «Peste des 
TABLEAUं I. - Côte-d'Ivoire

\begin{tabular}{|c|c|c|c|c|}
\hline ANNÉE & $\begin{array}{c}\text { SITUATION } \\
\text { toyers et nombre }\end{array}$ & $\begin{array}{l}\text { EFFECTIF } \\
\text { troupeau }\end{array}$ & MALADFS & MORTS \\
\hline 1940 & $\begin{array}{l}\text { M'BAYAKRO } \ldots \ldots \ldots \ldots \ldots \ldots \\
\text { VAVOUA } \ldots \ldots \ldots \ldots \ldots \ldots \\
\text { BOUAFLE } \ldots \ldots \ldots \ldots \ldots \ldots\end{array}$ & $\begin{array}{c}? \\
? \\
148 \mathrm{M} \\
177 \mathrm{C}\end{array}$ & $\begin{array}{l}- \\
- \\
-\end{array}$ & $\begin{array}{c}\text { Plusieurs, containes } \\
- \\
65 \\
95\end{array}$ \\
\hline 1941 & $\begin{array}{l}\text { ZUENOULA }(3) \ldots \ldots \ldots \ldots \\
\text { DIEBOUGOU (3) } \ldots \ldots \ldots \ldots\end{array}$ & - & $\begin{array}{l}22 \mathrm{M} \\
64 \mathrm{C} \\
24 \mathrm{M} \\
58 \mathrm{C}\end{array}$ & $\begin{array}{r}1 \mathrm{M} \\
39 \mathrm{C} \\
3 \mathrm{M} \\
8 \mathrm{C}\end{array}$ \\
\hline 1942 & DIMBOKRO . . . & - & - & - \\
\hline 1943 & $\begin{array}{l}\text { BOUAKE } \ldots \ldots \ldots \ldots \ldots \ldots \ldots \\
\text { DALOA } \ldots \ldots \ldots \ldots \ldots\end{array}$ & 926 & 99 & $80:$ \\
\hline 1944 & $\begin{array}{l}\text { DALOA } \ldots \ldots \ldots \ldots \ldots \ldots \ldots \\
\text { SEGUELA } \ldots \ldots \ldots \ldots \ldots\end{array}$ & - & - & - \\
\hline 1945 & VAVOUA $\ldots \ldots \ldots \ldots \ldots$ & 399 & 137 & 21 \\
\hline 1946 & - & - & - & - \\
\hline 1947 & $\begin{array}{l}\text { DIMBOKRO } \ldots \\
\text { DABOU } \ldots \ldots\end{array}$ & $\begin{array}{c}706 \mathrm{M} \\
665 \mathrm{C} \\
165 \mathrm{M} \text { et } \mathrm{C}\end{array}$ & - & - \\
\hline 1948 & - & - & - & - \\
\hline 1949 & $\left.\begin{array}{l}\text { BOUAKE .... } \\
\text { Régions Sud.. }\end{array}\right\} 28 \ldots \ldots$. & - & - & $1.090 \mathrm{M}$ et $\mathrm{C}$ \\
\hline 1950 & - & - & - & - \\
\hline 1951 & $\begin{array}{l}\text { SEGUELA } \ldots \ldots \ldots \ldots \ldots \ldots \\
\text { DALOA }(+12) \ldots \ldots \ldots \ldots \ldots \\
\text { BASSE COTE } \ldots \ldots \ldots \ldots \ldots\end{array}$ & - & - & $+500 \mathrm{M}$ et $\mathrm{C}$ \\
\hline 1952 & $\left.\begin{array}{l}\text { DALOA..... } \\
\text { GAGNOA ... } \\
\text { MAN....... } \\
\text { SASSANDRA.. }\end{array}\right\} 23 \ldots \ldots \ldots$. & $\begin{array}{c}3.758 \\
:\end{array}$ & 1.942 & 1.675 \\
\hline 1953 & 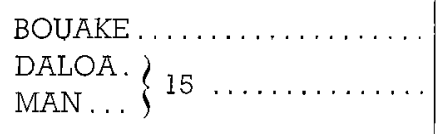 & $\begin{array}{r}356 \\
1.063\end{array}$ & - & $\begin{array}{l}109 \\
338\end{array}$ \\
\hline 1954 & $\left.\begin{array}{l}\text { MAN ........ } \\
\text { GAGNOA ... } \\
\text { BOUAKE } \ldots . . \\
\text { ZOUENOUL } \Lambda .\end{array}\right\} 25 \ldots \ldots \ldots$ & 2.942 & 577 & 594 \\
\hline
\end{tabular}


TABLEAU II. - Dahomey

\begin{tabular}{|c|c|c|c|c|}
\hline ANNÉE & $\begin{array}{c}\text { SITUATION } \\
\text { foyers et nombre }\end{array}$ & $\begin{array}{l}\text { EFFECTIF } \\
\text { troupeau }\end{array}$ & MALADES & MORTS \\
\hline 1941 & $\begin{array}{l}\text { PARAKOU } \ldots \ldots \ldots \ldots \ldots \ldots \\
\text { NIKKI } \ldots \ldots \ldots \ldots \ldots \ldots \ldots \\
\text { KANDI } \ldots \ldots \ldots \ldots \ldots \ldots\end{array}$ & $\begin{array}{l}- \\
-\end{array}$ & - & $\begin{array}{l}- \\
-\end{array}$ \\
\hline 1942 & $\begin{array}{l}\text { OUEDEME } \ldots \ldots \ldots \ldots \ldots \ldots \ldots \\
\text { TOUROU } \ldots \ldots \ldots \ldots \ldots \ldots \ldots\end{array}$ & - & - & - \\
\hline 1943 & $\left.\begin{array}{l}\text { SAVALOU } \ldots \ldots \ldots \ldots \ldots \ldots \\
\text { NIAOULI } \ldots \ldots \ldots \ldots \ldots \ldots\end{array}\right\}$ & $\mathrm{X}$... Moutons & - & - \\
\hline 1944 & COTONOU $(1) \ldots \ldots \ldots \ldots \ldots$ & - & - & - \\
\hline 1945 & ALLADA $(1) \ldots \ldots \ldots \ldots \ldots$ & - & - & - \\
\hline 1946 & $\begin{array}{l}\text { COTONOU } \ldots \ldots \ldots \ldots \ldots \ldots \\
\text { OUIDAH } \ldots \ldots \ldots \ldots \ldots \ldots \ldots \\
\text { PORTO-NOVO } \ldots \ldots \ldots \ldots \ldots\end{array}$ & - & - & - \\
\hline 1947 & COTONOU. . . . . . . . . . . . . & - & - & - \\
\hline 1948 & DJOUGOU $\ldots . .$. & - & - & - \\
\hline 1949 & $\begin{array}{l}\text { NIKKI } \ldots \ldots \ldots \ldots \ldots \ldots \ldots \\
\text { COTONOU } \ldots \ldots \ldots \ldots \ldots \ldots\end{array}$ & - & - & - \\
\hline 1950 & Régions Sud........... & - & - & - \\
\hline 1951 & $\begin{array}{l}\text { PARAKOU } \ldots \ldots \ldots \ldots \\
\text { NIKKI } \ldots \ldots \ldots \ldots \\
\text { SAVALOU } \ldots \ldots \ldots \ldots\end{array}$ & - & $\begin{array}{l}- \\
- \\
-\end{array}$ & $\begin{array}{c}280 \mathrm{M} \text { et } \mathrm{C} \\
-\mathrm{C} \text {. } \mathrm{C}\end{array}$ \\
\hline 1952 & $\begin{array}{l}\text { PORTO-NOVO } \ldots \ldots \ldots \ldots \ldots \\
\text { COTONOU } . \\
\text { OUIDAH } \ldots \ldots \ldots \ldots \ldots \\
\text { ABOMEY } \ldots \ldots \ldots \ldots \ldots \ldots \\
\text { DJOUGOU } \ldots \ldots \ldots \ldots \ldots \ldots\end{array}$ & $\begin{array}{l}- \\
- \\
- \\
-\end{array}$ & $\begin{array}{l}2.122 \\
?\end{array}$ & $\begin{array}{l}573 \\
?\end{array}$ \\
\hline 1953 & $\begin{array}{l}\text { NATITINGOU (1) } \ldots \ldots \ldots \ldots \\
\text { PORTO-NOVO }(1) \ldots \ldots \ldots\end{array}$ & - & $\begin{array}{r}155 \\
21\end{array}$ & $\begin{array}{r}17 \\
1\end{array}$ \\
\hline 1954 & $\begin{array}{l}\text { COTONOU (2) } \ldots \ldots \ldots \ldots \\
\text { OUIDAH (1) } \ldots \ldots \ldots \ldots \ldots \\
\text { PORTO-NOVO }(1) \ldots \ldots \ldots \\
\text { PARAKOU }(4) \ldots \ldots \ldots \ldots \\
\text { DJOUGOU }(4) \ldots \ldots \ldots \ldots \\
\text { NATITINGOU }(1) \ldots \ldots \ldots \ldots\end{array}$ & $?$ & $\begin{array}{r}40 \\
5 \\
13 \\
80 \\
19 \\
5\end{array}$ & $\begin{array}{r}15 \\
0 \\
2 \\
2 \\
15 \\
3\end{array}$ \\
\hline
\end{tabular}


petits ruminants » dans d'autres Territoires côtiers du Sud. Il semble en effet que les ovins et caprins de ces régions soient plus sensibles à cette affection que ceux du Nord (Sahel). (Nous retrouvons là une épizootologie superposable à celle de la peste bovine, les bovins du Sahel offrant une résistance plus grande que ceux des zones méridionales).

Les pertes sont mal' connues, les éleveurs déclarent raroment les foyors qui interviennent sur un potit bétail numériquement très fragmenté, par famille ou case, et de façon sporadique. La morbidité et la mortalité sont cependant, au cours de certaines années, très importantes, et c'est une des raisons qui ont attiré l'attention des vétérinaires, au cours, de leurs tournées, en dépit de la discrétion des propriétaires.

Ie bilan des enzooties observées en Côte-d'Ivoire et au Dahomey, le plus souvent accidentellement, est résumé dans les tableaux ci-dessus.

Il est aisé de se rendre compte que les renseignements fournis sont souvent incomplets et certains chiffres obtenus des éleveurs sont sujets à caution.

En 1943, le chef 'du Service de l'Élevage du Dahomey écrit : "Jamais encore cette maladie ne nous a été signalée par les éleveurs de la brousse. Des foyers ont pourtant été découverts dans les villages isolés par des infirmiers en tournée. Dans ce cas, une partie des moutons et des chèvres avaient été atteints, avec une grosse mortalité, surtout chez les caprins. Nous pensons que cette maladie doit causer annuellement d'assez gros 'dégâts... ).

En 1946, il confirme ces données et ajoute : « Des renseignements recueillis dans le Cercle d'Athiémé, pendant le recensement, permettent de croire que le cheptel ovin et caprin de certains villages a été dévasté par cette maladie sans que nous soyons prévenus ». En 1951, il estime que les villages de Savalou, Oueme Ouagui et Gboffa ont perdu $75 \%$ de leur effectif ovin-caprin.

Le chef du Service de la Côte-d'Ivoire est exactement du même avis concernant l'épizootologie et la non-déclaration de l'affection (1952).

\section{Épizootologie}

La maladie apparaît tantôt de façon sporadique, tantôt en foyers plus ou moins groupés. Certaines années, elle se développe en véritables épizooties, entraînant la mort de centaines d'animaux.

Ellè est liée à la virulence du contage, à la réceptivité des animaux et à la forme de l'élevage, le plus souvent familial.

Les groupements d'ovins et caprins sont très favorables à l'éclosion de la « Peste des petits ruminants \%, Nous en avons, deux exemples très démonstratifs : l'un à Dakar où l'acquisition de chèvres dans divers villages de la région de Kaolack déclenche la maladie, le deuxième à Bouaké sur des sujets achetés dans la région de Korhogo, justement dans le but de mettre en route une expérimentation sur la «Peste des petits ruminants». - Dans ce dernier cas, la maladie se manifeste au moment de pratiquer l'inoculation du virus P.P.R.

Cette épidémiologie particulière soulève divers problemes. L'apparition de novo de la P.P.R., consécutive à une modification de l'habitat et du régime alimentaire des caprins, animaux très sensibles aux circumfusa, constitue un argument non négligeable en faveur de l'existence des provirus (Jacob, 1954), des virus endormis (Hauduroy, 1954); ou du moins, puisque des observations semblables n'ont pas été faites chez les animaux supérieurs, ramène à la notion des « Porteurs et Vecteurs de germes microbiens » (Ramon, 1956).

Et dans ce cas, la zone d'expansion de la P.P.R. est certainement plus étendue que nous ne le pensons et le virus doit se maintenir dans, des régions considérées comme indemnes.

\section{Symptomatologie}

Compte tenu des observations faites en Côted'Ivoire, au Dahomey et à Dakar, la maladie se présente sous trois formes :

\section{a) Suraiguë :}

La période d'incubation est de 2 jours en moyenne et l'évolution de 5-6 jours. La température s'élève à $40-41^{\circ}$, voire $42^{\circ}$ le soir. L'animal présente les signes généraux des grandes infections : anorexie. poil piqué (aspect "frileux»), état typhique. La constipation, de règle au début, est suivie de diarrhée, avec la plupart dú temps présence de coccidies.

Un léger jetage séro-muqueux souille les naseaux. Les lésions buccales (ulcérations gingivales); ne sont pas constantes. Mais il existe toujours 'une congestion des gencives. Une toux d'irritation pharyngo-laryngienne est fréquemment observée.

Cette forme évolue vers une mort brutale, après une courte période d"hypothermie.

L'animal peut guérir rapidement, sans présenter la moindre séquelle.

\section{b) Aiguë :}

La période d'incubation est allongée : 3 à 4 jours. Et l'évolution de la maladie est de 8 à 10 jours. La fièvre peut être aussi intense mais la période de résistance à l'infection est allongée, aussi lẹs lésions ont-elles le temps d'apparaître. 


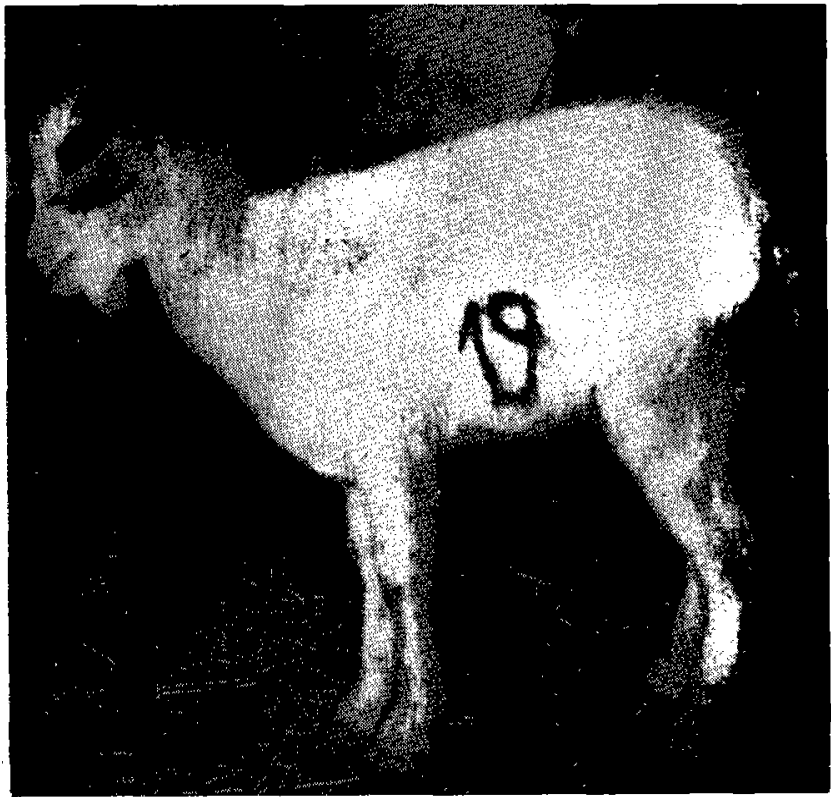

Figure 1.

État typhique du malade au début.

Noter l'aspect "frileux ».

Un léger jetage séro-muqueux se manifeste qui devient muco-purulent. Les yeux sont fortement humides mais il n'y a pas de véritable larmoiement avec inflammation conjonctivale. Vers le 5 e ou $6^{e}$ jour, on constate une vive congestion des gencives, puis une stomatite ulcéro-nécrotique sur les gencives et la face interne des levres, la langue, le pharynx. La bouche exhale une odeur létide.

Ia toux fait généralement son apparition à ce stade, mais elle n'est pas constante. La djarrhée coccidienne est fréquente. L'animal ne s'alimente plus et maigrit. Les complications les plus fréquemment observées sont la broncho-pneumonie avec ou sans pleurésie exsudative, les "sorties" d'hématozoaires : Piroplasma ovis, Theileria recondita, Anaplasma ovis, Trypanosoma vivax et congolense...

Chez les femelles, une inflammation vulvo-vaginale avec muco-pus n'est pas rare. Les gestantes arortent régulièrement.

L'affection évolue soit vers la mort, soit vers la chronicité, soit vers la guérison.

En général, lorsque la maladie est compliquée de broncho-pneumonie ou d'hématozooses, la mort est de règle.

Cette forme de l'affection est essentiellement caractérisée par une stomatite ulcéro-nécrotique.

\section{c) Subaiguë ou chronique :}

L'évolution s'effectue en 10 à 15 jours et fait suite habituellement à la forme aiguë. Mais elle peut intervenir d'emblée sans stomatite primitive. Après une phase fébrile modérée, la fièvre s'installe en plateau : $39^{\circ} 5-40^{\circ} 5$. Il apparait vers le $10^{\mathrm{e}}$ jour du muco-pus à la commissure des lèvres tandis qu'on note des papules, puis des pustules à la périphérie des orifices buccal et nasal, principalement sur le menton. Peu à peu, des croûtes épaisses recouvrent la peau à l'endroit des pustules. Les lésions sont identiques à celles de l'ecthyma. Si l'on soulève la croûte, la peau apparait rosée, recouverte d'un léger enduit pultacé blanchâtre. I:a croûte enlevée se reforme rapidement.

Lorsque l'orifice nasal du canal lacrymal est atteint, il y a dacryocystite et palpébrite. Les paupières sont parfois recouvertes de croûtes de même que la peau avoisinante. L'odeur de la cavité buccale est généralement infecte et la stomatite identique à celle de la forme précédente.

L'animal ne s'alimente plus, s'amaigrit, et la mort se produit dans le marasme.

Des complications de broncho-pneumonie, péritonite, etc., peuvent survenir.

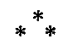

Ainsi, l'étude clinique de la P.P.R. présente bien

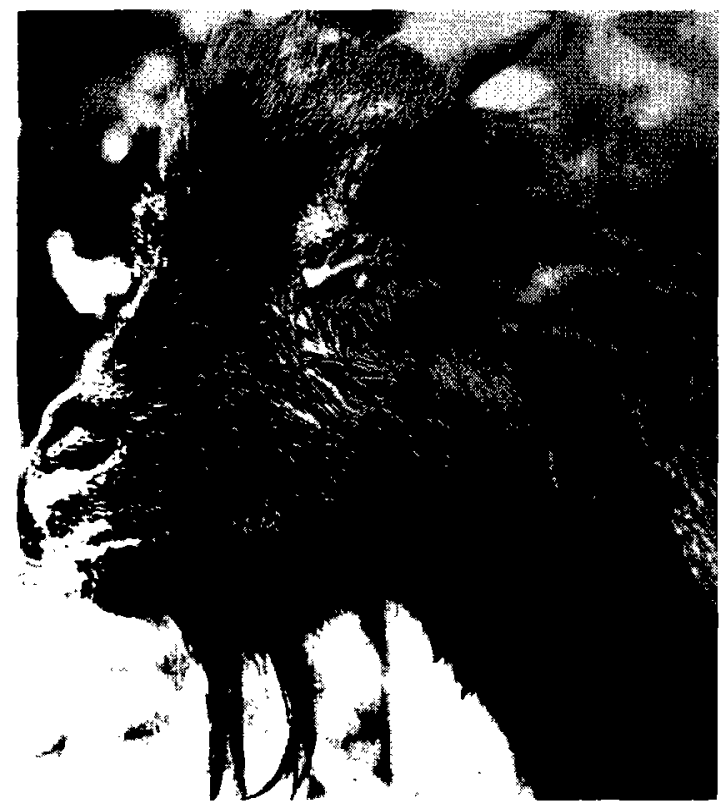

Figure 2.

Jetage muco-purulent. Stomatite ulcéro-nécrotique. Inflammation conjonctivale. 


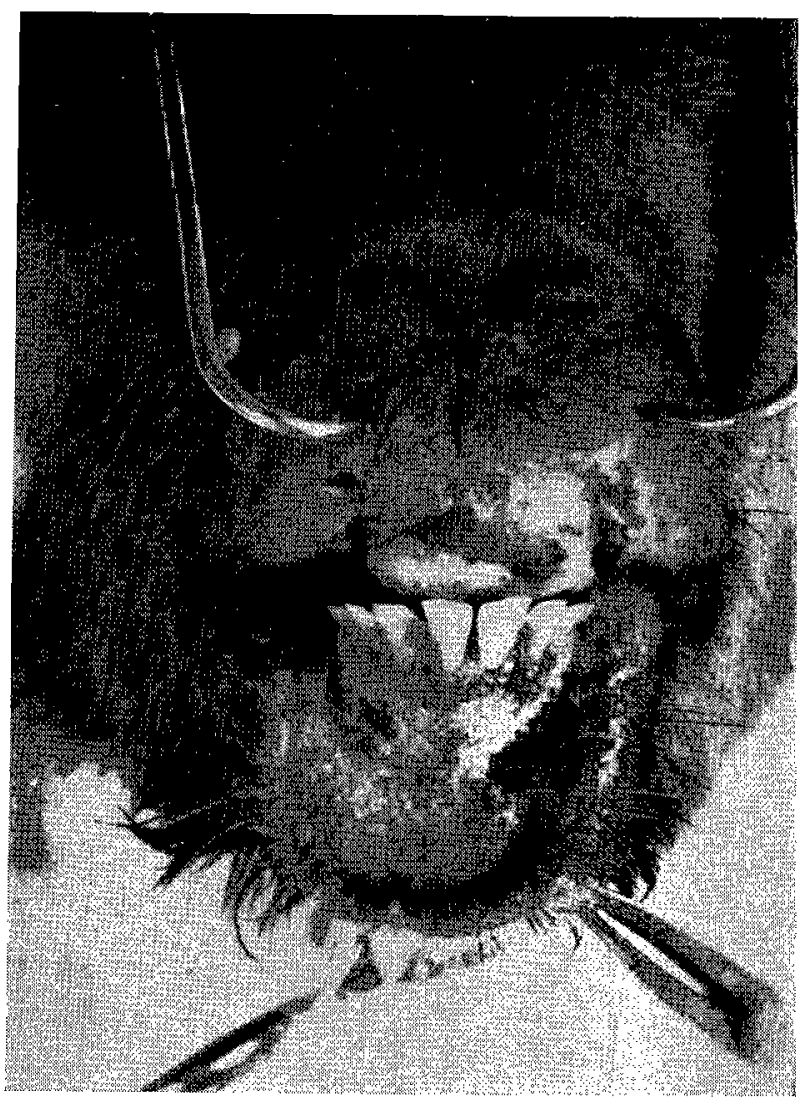

Figure 3.

Ulcérations et enduit pultacé sur les gencives.

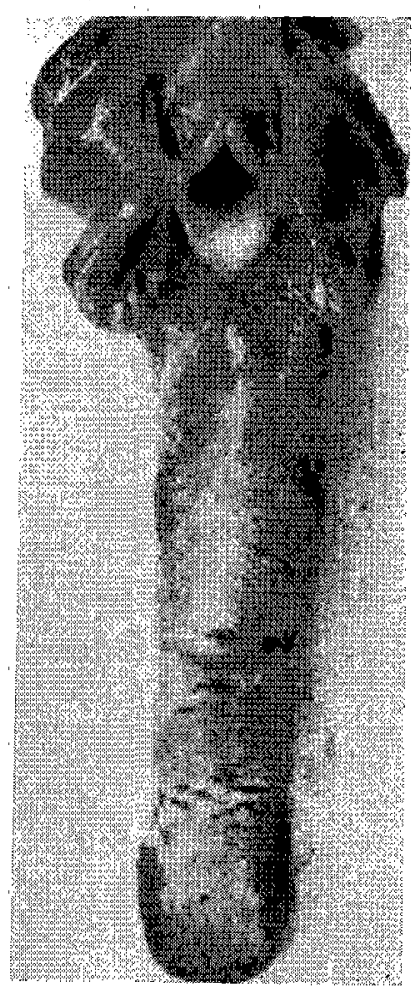

Figure 4.

Ulcérations de la langue.

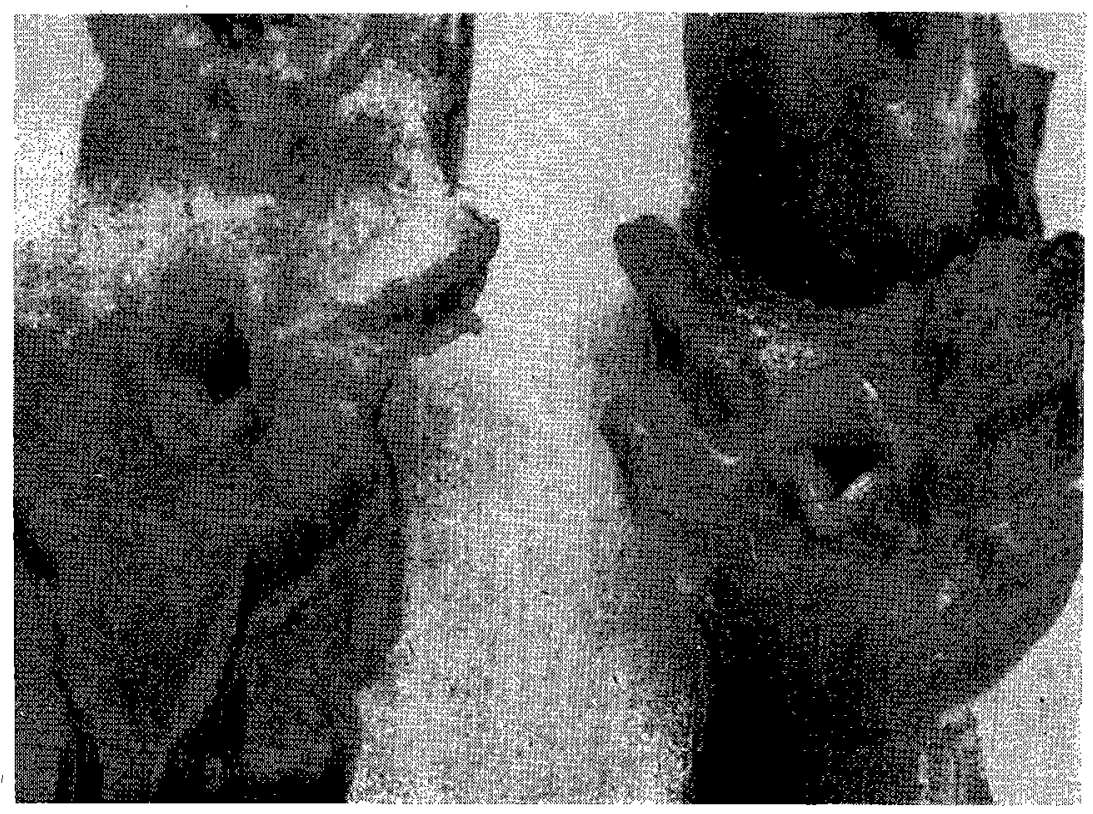

Figure 5.

Ulcérations et enduit pultacé sur le pharynx. 


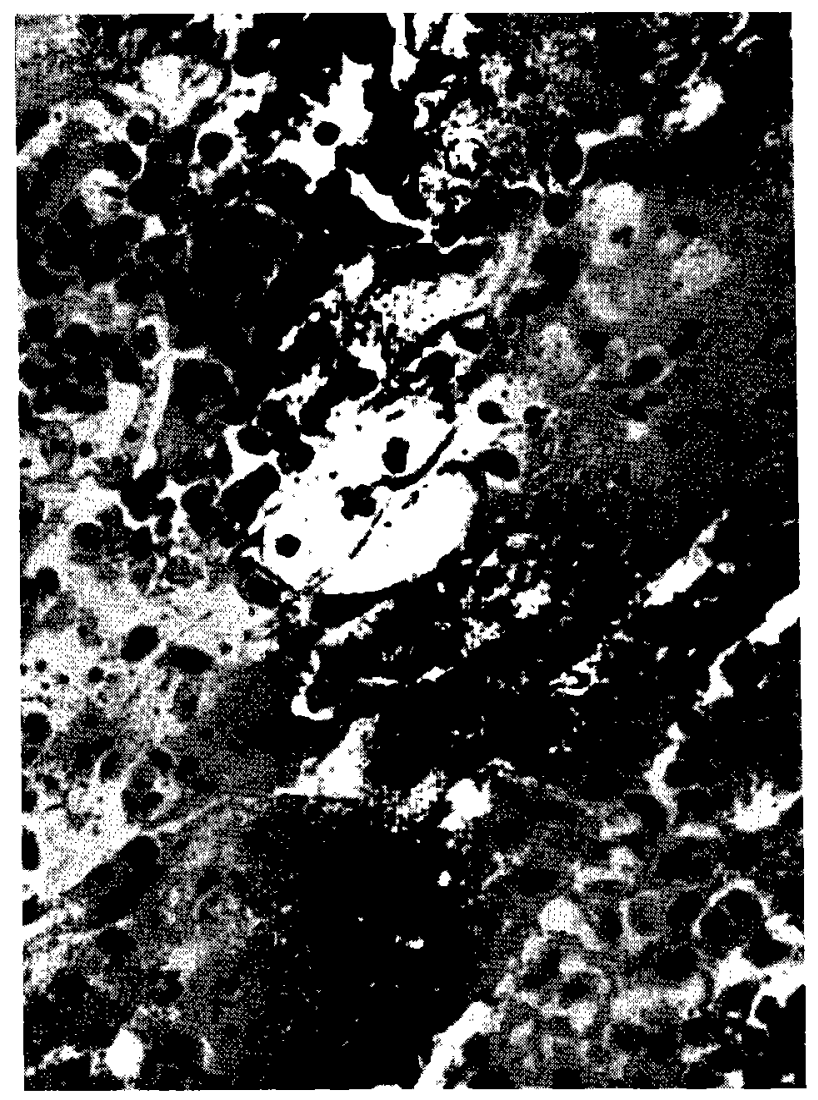

Figure 6.

Coupe à travers la paroi d'une crypte amygdalienne montrant dans la lumière (en bas à droite) des polynucleaires en voie de nécrose, et de très nombreuses inclusions cellulaires. Celles-ci représentées en noir, entourées d'un petit halo clair, sont de forme et de taille variables. Elles prennent naissance au contact du noyau. (Mann $\times$ 600.)

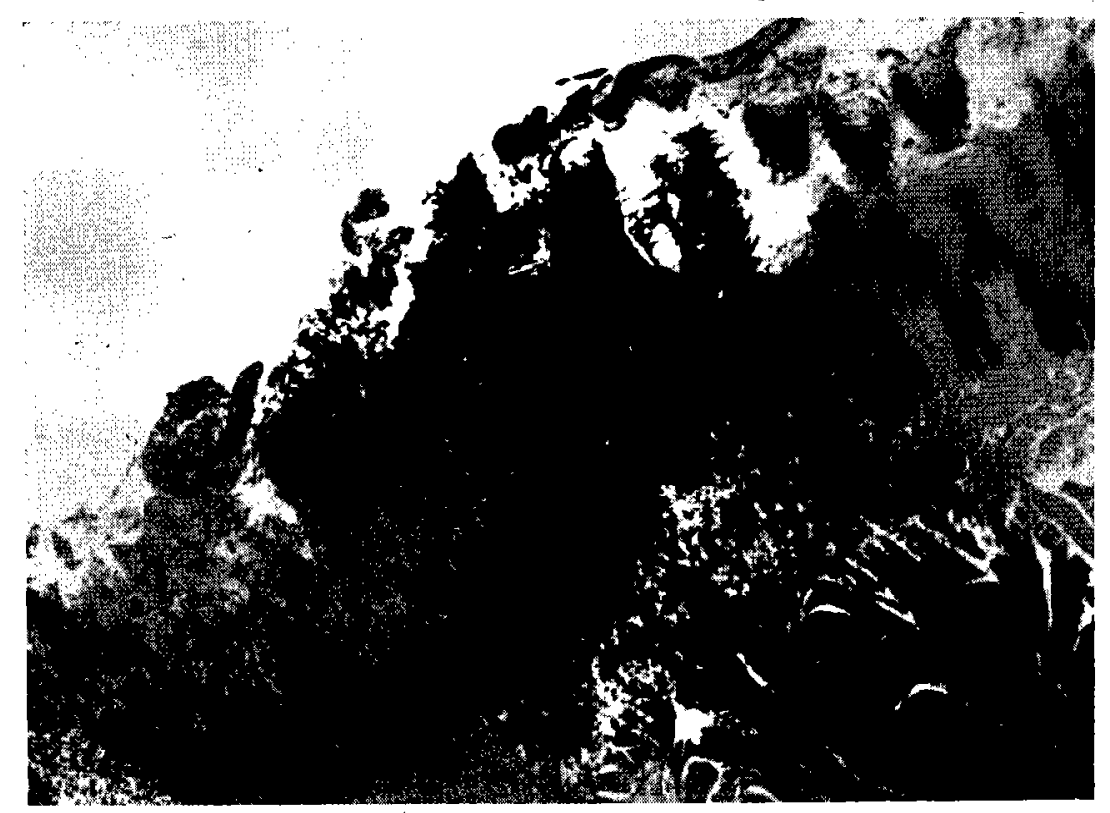

Figure 7.

Lésion linquale récente. L'épithélium est normal à droite, à gauche toute structure est cachée par l'infiltration lymphocytaire. Le chorion papillaire est le siège d'une intense diapédèse. (Trichrome de Masson $\times 50$. .) 
des points communs avec la peste bovine. On peut, comme pour cette dernière, schématiser en quatre phases l'évolution aiguë :

Période d'incubation : 2-3 jours.

Période d'invasion : 1-2 jours.

Période des lésions externes : 2-3 jours.

Période des signes gastro-intestinaux : 2-3 jours.

Les deux demières périodes sont parfois superposées ou inversées, comme dans la peste bovine, mais l'évolution entré en général dans le cadre symptomatologique.

Il est à noter que les chèvres malades présentent assez souvent des signes de pneumonie ou de broncho-pneumonie, avec, ou sans exsudation pleurale.

Il y a là une différence importante avec la peste bovine du gros bétail où l'atteinte pulmonaire n'existe pas.

Par contre, elle n'est pas rare dans la peste bovine des petits ruminants, dans l'Inde.

La plupart des auteurs notent cette sensibilité du parenchyme pulmonaire des chèvres, non spécifique d.une affection particulière mais inhérente aux aninaux de cetle espèce, qui réagissent ainsi à diverses agressions.

\section{Lésions}

\section{a) Forme suraiguë :}

L'autopsie d'un animal mort de la forme suraiguë ne permet pas de noter la moindre lésion ou tout au plus une congestion de la valvule iléo-cæecale.

Parfois, il existe une broncho-pneumonie secondaire.

\section{b) Forme aiguë :}

Les lésions observées, classées par appareil, sont les suivantes :

\section{Appareil digestif :}

Stomatite congestive, ulcéreuse, nécrotique, ulcéro-nécrotique, siégeant, sur les gencives et la face interne des lèvres, les joues, la langue et le pharynx ou sur l'une seulement de ces régions.

Congestion de la valvule iléo-çecale si la mort n'est pas trop précoce.

Souvent entérite parasitaire (strongylose, coccidiose).

Appareil respiratoire : rhinite séreuse ou mucoséreuse, laryngite légère muco-séreuse.

Parfois broncho-pneumonie à foyers confluents des lobes apicaux et de l'extrémité des lobes cardiaques.

Appareil hémolymphopoïétique : très légère splénomégalie, œdème des divers ganglions, surtout accusé pour les ganglions mésentériques.
Système nerveux : légère congestion de la substance grise médullaire et de la base du cerveau.

\section{c) Forme chronique :}

A ces lésions s'ajoutent une péristomatite et une périnasalite croûteuses.

\section{Histopathologie}

Les muqueuses recouvertes d'un épithélium malpighien sont chez l'animal affecté le siege de l'atteinte la plus importante; aussi allons-nous commencer par la description de leurs lésions.

10 Tissus épithéliaux stratifiés pavimenteux (malpighiens et para-malpighiens)

Les lésions de la muqueuse bucco-pharyngienne sont de même nature chez les bovins pestiques et chez les petits ruminants affectés par la peste qui leur est spécifique. Néanmoins, on constate chez ces derniers animaux, une intensité plus grande de l'infiltration par les polynucléaires qui constituent, mélangés aux débris épithéliaux, un épais enduit basophile à la surface des ulcérations. De nombreux germes microbiens et même des filaments: mycéliens cultivent sur cet enduit. Tandis que les plasmodes épithéliaux sont peu nombreux ou rares dans la peste bovine, ils sont fréquents dans ia peste des petits ruminants. Ici encore, on décèle, lorsque la lésion débute, une importante consommation de ribonucléoprotéines du corps de Malpighi et, par la suite, la constitution d'inclusions cellulaires cytoplasmiques acidophiles.

Dans l'épithélium amygdálien, les inclusions cytoplasmiques sont nombreuses ainsi que les lésions de dégénérescence nucléaire spécifique. Les images observées sont souvent plus démonstratives que celles que l'on remarque chez les bovins.

Alors que, si l'affection est suraiguë, on peut ne rencontrer que des lésions épithéliales microscopiques ou même l'absence totale de lésions, lors d'affection 'chronique, les ulcérations sont très étendues, recouvertes d'un abondant magma infiltré de polynucléaires. Parfois on note, en certains points, des signies de guérison qui se traduisent par l'élimination totale des éléments nécrosés et la régénération de l'épithélium à partir de l'assise génératrice.

L'œsophage et lés réservoirs digestifs présentent des lésions microscopiques analogues à celles de l'épithélium buccal' mais habituellement sans inclu'sions cellulaires et pauvres en plasmodes.

La peau de la face externe des lèvres montre, dans les premiers stades, des microabcès intraépithéliaux exactement semblables à ceux que l'on observe chez les bovins pestiques, mais, tandis 
que chez les grands ruminants la lésion ne dépasse pas ce stade, chez les petits ruminants, lors de forme subaiguë ou chronique, elle devient très importante. L'image histologique, d'abord semblable à celle de l'ulcération étendue de la muqueuse buccale, se complique par une inflammation vraie du chorion. On peut dès lors mettre en évidence sous la croûte formée de débris épithéliaux et de polynucléaires dégénérés, outre des staphylocoques, des germes fusiformes, parfois même spirillaires,
Enfin, la conjonctive palpébrale présente les mêmes images que chez les taurins, accompagnées fréquemment de congestion accusée du chorion.

\section{$2^{\circ}$ Muqueuses à épithélium cylindrique simple}

Alors que nous avons observé une parenté très étroite des lésions des épithéliums malpighiens chez les grands et les petits ruminants affectés de la peste qui leur est propre, on va constater une différence au niveau de la muqueuse digestive.

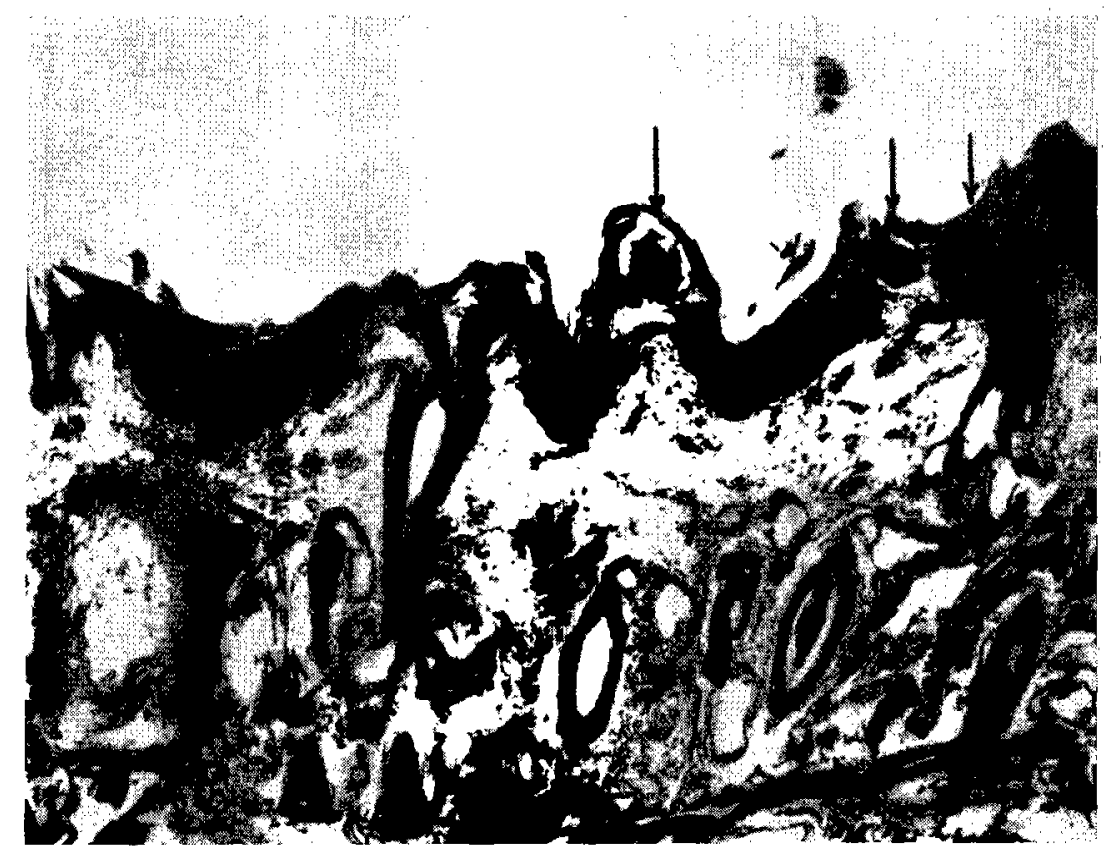

Figure 8 .

Lésion épithéliale péribuccale débutante, se traduisant par la formation de microabcès intraépithéliaux (au niveau des flèches). (Hématoxyline - éosine $\times 50$.)

que l'on retrouve au niveau des ulcérations de la face interne des lèvres. C'est ce qui explique l'odeur nauséabonde de la stomatite et surtout de la péristomatite.

La différence d'aspect de ces lésions pestiques chez les grands et les petits ruminants résulte d'une complication septique des abcès intra-épithéliaux primitifs.

La muqueuse du fourreau, de même que celle de la vulve et parfois celle du vagin, présente d'abord au voisinage de la limite cutanéo-muqueuse, puis sur toute l'étendue de la muqueuse, une infiltration leucocytaire et des plasmodes typiques de l'atteinte virale des épithéliums malpighiens. On peut $y$ déceler quelques inclusions cellulaires acidophiles.
Il convient de noter, ici, en premier lieu, l'absence de lésion gastrique. Par contre, l'intestin grêle renferme de nombreuses inclusions cellulaires. Elles s'observent dans la portion terminale de l'iléon, principalement dans l'épithélium situé en regard des formations lymphoïdes, plus rarement dans le reste de l'intestin. Elles siègent dans les entérocytes des villosités, et en plus faible proportion dans les glandes de Lieberkühn. Elles sont tantôt peu abondantes, tantôt si nombreuses que la plupart des cellules à plateau strié en renferment. En raison de la bipolarité de ces cellules, elles s'observent soit à l'apex, soit à la base des entérocytes; elles ont parfois une forme allongée en boudin. On retrouve, comme chez les bovins, l'infiltration du chorion de la muqueuse intestinale par des 
polynucléaires éosinophiles; conséquenco de l'agros sion virale. On remarque également la nécrose des leucocytes qui diapédèsent à travers l'épithélium mais en faible proportion.

La muqueuse de la trachée est parfois le siège d'une légère inflammation, mais, même en l'absence de celle-ci, on y rencontre généralement des inclusions cellulaires cytoplasmiques acidophiles, incluses dans les cellules ciliées.

Les cellules de l'épithélium bronchique ne ren-
50 Organcs cxcrćtcurs.

Le rein est le siège d'une filtration glomérulaire d'albumine et parfois d'une légère néphrite épithéliale.

\section{Parenchyme pulmonaire.}

Le poumon est très intéressant à considérer dans la peste des petits ruminants. Il est, en effet, le siège, fréqucmment, do broncho-pneumonic localisée aux lobes apicaux et cardiaques. I'image histologique

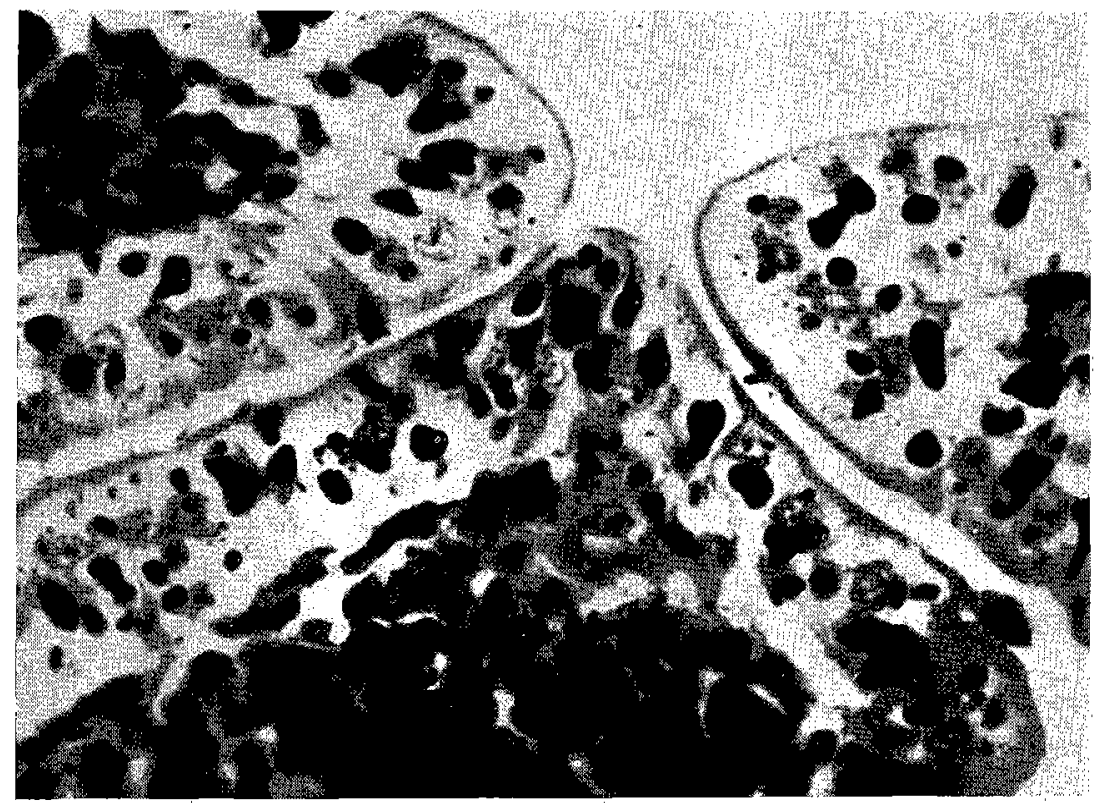

Figure 8.

Coupe des villosités de l'iléon permettant d'observer dans l'épithélium de très nombreuses inclusions supra ou infra-nucléaires. Il est exceptionnel de rencontrer une telle abondance d'inclusions cellulaires cytoplasmiques. (Mann $\times 600$.)

forment des inclusions que lorsqu'il cxiste uno bronchite ou une pneumonie de type interstitiel sur laquelle nous allons revenir dans quelques instants.

\section{$3^{\circ}$ Autres épithéliums.}

Contrairement à ce qui existe chez les bovins, tous les autres épithéliums sont normaux, notamment l'épithélium wolffien.

\section{Parenchymes glandulaires.}

Les parenchymes glandulaires présentent les mêmes modifications que chez les bovins. Quelques cellules périlobulaires hépatiques manifestent des signes de souffrance. Les glandes endocrines montrent, selon lé stade évolutif de la maladie, des figures d'hyperactivité ou d'épuisement. cst différcnte sclon les cas. On peut rencontror tantôt une broncho-pneumonie banale évoluant vers le stade alvéolite purulente; tantôt associés à la précédente, des foyers de pneumonie interstitielle où I'on identifie une intense réaction alvéolaire avec formation de plasmodes géants qui peuvent recéler plusieurs inclusions cellulaires cytoplasmiques. On décèle des lobules de pneumonie interstitielle presque pure tandis que d'autros sont affectés d'al véolite purulente. Les deux phénomènes paraissent bien se superposer; ils ne se mélangent pratiquement pas. On est, dès lors, habilité à se demander si l'on n'est pas en présence, dans un cas, d'une virose, dans l'autre, d'une affection microbienne banale, la virose pulmonaire paraissant elle-même différente de la peste des petits ruminants puisque 


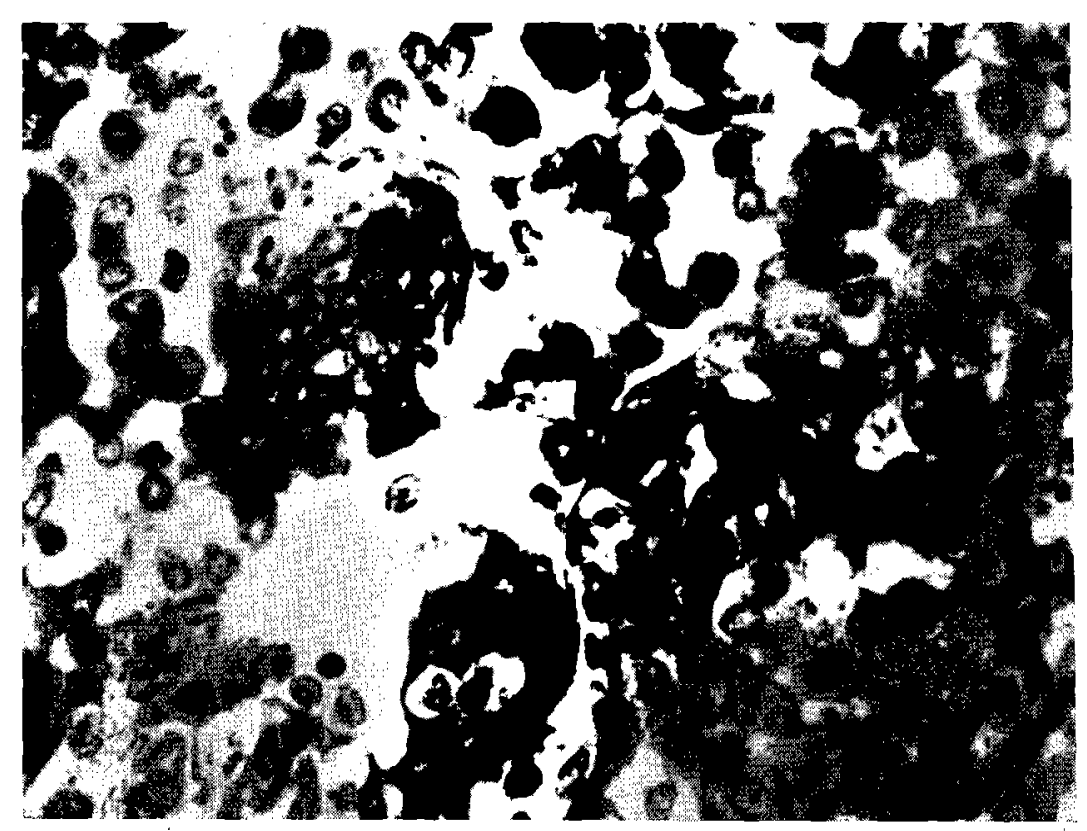

Figure 10.

Sur la coupe du poumon on remarque, à gauche, un plasmode géant renfermant des inclusions cellulaires et, à droite, une zone de pneumonie caractérisée par l'hyperplasie et l'hypertrophie des cellules alvéolaires chargées d'inclusions cellulaires (fixation et coloration de Flemming $\times 600$.)

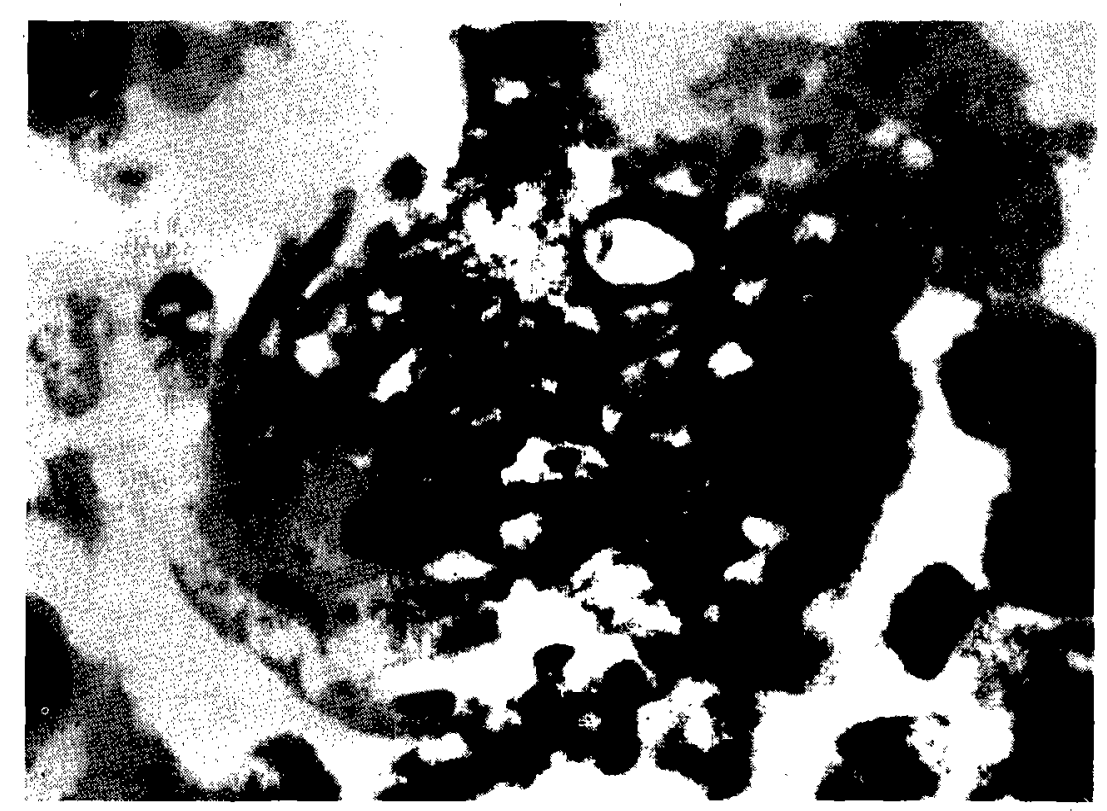

Figure 11 .

Fort grossissement d'un plasmode pulmonaire montrant le nombre important des noyaux et la variété de forme, de taille et de nombre des inclusions cellulaires. (Flemming $\times 1500$.) 
constante dans certains lots d'animaux et absente dans d'autres. La broncho-pneumonie représenterait dès lors, lorsqu'elle existe, une forme de sortie de la peste. C'est ce qui fait comprendre encore que l'on puisse observer d'une manière aussi discrète la lésion pulmonaire de type viral puisqu'elle n'a pu évoluer qu'à partir du moment où la peste des petits ruminants s'est développée. Bien plus, le virus de la pneumonie a dû souiller des prélèvements renfermant le virus de la peste des petits ruminants, ce qui explique la pneumionie de certains lots d'animaux d'expérience.

\section{Organes hémolymphopoïétiques.}

Ils ne sont que peu lésés. La lésion lymphoïde élémentaire est très discrète bien que procédant du même mécanisme que chez les bovins. La nécrose du centre germinatif des follicules est rarement observée. Néanmoins, la déshabitation des sinus lymphatiques des ganglions se produit comme chez les bovins, ce qui entraîne des réactions sanguines de 'même nature que' dans la peste bovine.

\section{$8^{\circ}$ Autres tissus.}

Le système nerveux est peu, lésé, tout au plus observe-t-on une chromatolyse des cellules pyramidales corticales et du bulbe; et, d'une manic̀re exceptionnelle, des images de neuronophagie.

Comme chez les bovins, la dégénérescence cireuse des muscles, lorsqu'elle existe, est très discrète.

Les autres tissus sont normaux, notamment le placenta des femelles gestantes.

\section{Les lésions spécifiques.}

Elles sont de même nature que chez les bovins. Elles comportent des inclusions cellulaires et des figures de dégénérescence nucléaire particulières.

Les inclusions cellulaires présentent les mêmes caractèros quo chez les bovins. Lcur nature histochimique est semblable. Elles ne se rencontrent pas dans les cellules en voie de mortification. Comme il a été signalé précédemment, lés inclusions de l'épithélium de l'intestin sont beaucoup plus abondantes que chez les grands ruminants, et il en existe dans l'épithélium de la trachée. Par contre, nous n'avons observé qu'exceptionnellement des inclusions dans les follicules lymphoïdes. Les inclusions intestinales méritent une mention particulière car elles sont parfois très grosses et les corpuscules internes sont bien visibles. La réaction de Feulgen à leur niveau est relativement intense.

Les figures de dégénérescence nucléaire se rencontrent plus fréquemment que chez les bovins. De même les plasmọdes épithéliaux sont beaucoup plus abondants'aux licux d'élcction dans la peste des petits ruminants que dans la peste bovine.

\section{$* *$}

L'étude histopathologique met, ainsi en évidence une parenté étroite entre les lésions de la peste bovine des bovins et celles de la peste des petits ruminants. Cette constatation, associée au fait que l'on note la présence de lésions spécifiques de type viral, plaide en faveur, d'une part, de la nature virale de l'affection, d'autre part, de la parenté étroite des virus de la beste bovine et de la peste des petits ruminants. Cependant, l'épithéliotropisme de ce dernier virus semble plus prononcé que celui de la peste bovine. Cela ne doit pas, pour autant, surprendre, si l'on se rappelle que le virus bovipestique présente, un tropisme épithélial et lymphatique différent chez les bovins el les lapins.

\section{Étiologie}

La maladié est contagieuse et inoculable par injertion sous-cutanée ou intraveineuse de sang d'un animal malade.

Nalurellement, elle doit se propayer par les excreta (jetage, excréments diarrhéiques).

Aucun germe figuré responsable n'ayant pu être mis en évidence, compte tenu de l'épizootologie, de la symptomatologie, des lésions et de l'étude expérimentale, un virus doit être tenu pour responsable de la P.P.R.

\section{Diagnostic}

Les éléments essentiels pour l'établissement du diagnostic in vivo sont : la fièvre, l'inappétence, la stomatite ulcéro-nécrotique, 'la diarrhée.

Sur le cadavre: la congestion des cornets, du pharynx, de la valvule iléo-cæcale peuvent également orienter le diagnostic. Mais il est certain que ces signes cliniques ne sont pas univoques et doivent être étayés par. l'épizootologie et le diagnostic expérimental.

La «Peste des petits ruminants » doit être différenciée des affections suivantes :

\section{Peste bovine :}

La peste bovine naturelle du' mouton et de la chèvre n'a pas été observée en A.O.F., mais celle reconnue en Inde, par exemple, offre un tableau. clinique comparable. Les complications pulmonaires' sont également fréquentes. 
La maladie expérimentale, dans les cas positifs. offre, en Afrique occidentale, une symptomatologie sensiblement superposable à celle de la maladie naturelle.

\section{Pasteurellose :}

Les lésions de broncho-pneumonie, souvent surajoutées à la «Peste des petits ruminants», présentent beaucoup de caraclères de la pasteurellose. Majs les recherches microbiologiques effectuées permettent d'éliminer cette affection, la pasteurella, même comme germe de sortie, étant rarement mise en évidence dans les cas observés.

\section{Pleuro-pneumonie contagieuse des chèvres :}

Les premiers cas, enregistrés à Dakar, sont rattachés tout d'abord à cette entité. En effet, les signes cardinaux sont, dans certains cas, les mêmes: fièvre, essoufflement, toux fréquente et quinteuse, adynamie et les lésions superposables : bronchopneumonie avec pleurésie exsudative.

Mais il est impossible d'obtenir de cultures en bouillon-sérum de l'organisme responsable spécifique, classé actuellement dans le groupe des P.P.L.O.

Par la suite, les autres malades ne présentent plus de symptômes, ni dé lésions analogues aussi prononcées et aussi nettes. Mais, il est certainement difficile, sans le secours du laboratoire, d'assurer un diagnostic.

\section{Ecthyma contagieux des lèvres :}

A la période d'état de la maladie aiguë, où l'animal offre des lésions péribuccales, gingivales et linguales superposables à celles de l'ecthyma, il est très difficile, en se basant sur les signes cliniques, d'être affirmatif. L'âge des sujets, l'épizootologie, les inoculations expérimentales et l'analyse histopathologique peuvent.seules lever les doutes.

\section{Variole caprine :}

Les éruptions dans la variole caprine ont un caractère particulier, de même les localisations.

\section{Clavelée :}

Cette affection est spéciale au mouton et les pustules caractéristiques apparaissent d'abord dans les endroits glabres, ce qui permet d'orienter aisément le diagnostic. La clavelée n'est d'ailleurs pas inoculable par l'injection de sang de malade, au contraire de la «Peste des petits ruminants».

\section{Heart-water :}

Les formes subaiguës de heart-water, telles qu'on les rencontre généralement en A.O.F. sur les mou- tons et chèvres, ne peuvent prêter à confusion (signes nerveux en particulier), mais elles peuvent se superposer à la "Peste des petits ruminants » et perturber la symptomatologie.

La recherche systématique de Rickettsia 'ruminantium et le traitement à l'auréomycine doivent permettre d'éliminer les cas frustes de heart-water.

\section{Blue-tongue :}

Les signes généraux, les lésions buccales peuvent égarer l'observateur, mais cette affection est spéciale aux ovins, alors que la «Peste des petits ruminants " atteint surtout les chèvres. D'autre part, il ne semble pas y avoir dans la «Peste des petits ruminants » d'influence saisonnière comme dans la blue-tongue.

\section{Pronostic}

Il est variable, plus favorable généralement pour le mouton, moins réceptif, que pour la chèvre.

Suivant la virulence du contage, l'état des animaux, la mortalité s'établit de 10 à $90 \%$.

Cette affection semble en tout cas rendre très aléatoire l'élevage des petits ruminants en Côted'Ivoire et au Dahomey, en particulier.

\section{Prophylaxie}

A part les mesures sanitaires applicables aux affections contagieuses, aucune méthode de prophylaxie médicale n'est encore au point. Nos divers essais, relatés plus loin, sont encore insuffisants pour avoir quelque valeur.

\section{ÉTUDE EXPÉRIMENTALE DE IA IMALADIE}

Divers travaux ont été effectués par Gargadennec et Lalanne, en Côte-d'Ivoire (1940-1941), Cathou, au Dahomey (1941) et en Côte-d'Ivoire (1952), Bouvier, en Côte-d'Ivoire (1954).

Nous-mêmes, à Dakar et en Côte-d'Ivoire (en 1955), avons eu l'occasion d'expérimenter avec deux virus, l'un en provenance de Kaolack (Sénégal), l'autre de la région de Bouaké (Côte-d'Ivoire). Mais c'est en Guinée, en 1956, que nous avons pu réaliser l'étude la plus complète.

Nous diviserons donc le compte rendu expérimental en deux parties:

I. - Étude expérimentale « Dakar-Bouaké » (janvier-février-mars 1955).

II. — Étude expérimentale « Guinée »' (marsavril 1956). 


\section{PREMIÈRE PARTIE}

\section{ÉTUDE EXPÉRIMENTALE “ DAKAR-BOUAKÉ 》}

\section{A. - Avec le virus Kaolack}

Le virus est isolé de chèvres achetées à Kaolack (Sénégal) et devenues malades à la ferme du laboratoire. Mais il n'est pas certain que cette infection soit introduite de cette région car, quinze jours environ avant le premier décès (16/12/54), nous recevons d'une autre région du Sánégal, Kolda, 15 agnollos et 1 agneaux et. c'est un de ces derniers sujets qui meurt en premier lieu (le 17/1/55) dans des circonstances telles que l'autopsie n'est pas effectuée dans les meilleures conditions.

C'est l'enzootie dans le troupeau caprin (20 chevrettes et 29 chevreaux) qui retient notre attention. Elle est sévère et affecte aussi les moutons, mais de façon moins spectaculaire. Quatre-vingt-dix pour cent des chevrcttes et chcvreaux mourent et cinquante pour cent des moutons.

Le froid humide qui sévit à cette époque est peutêtre un facteur favorisant. Les premiers caprins morts présentent des lésions semblables à celles de la pleuro-pneumonie contagieuse, mais aucun Pleuropneumonia like organism ne peut être isolé.

Au fur et à mesure des décès, des ensemencements à partir des lésions pulmonaires et de la moelle osseuse sont effectués. Les úns sont négatifs, les autres mettent en évidence des germes variés: Pasteurella, Escherichia coli, de pathogénicité nulle ou faible.

Divers passages sont effectués sur des chèvres maures (de grande taille) ou de Kaolack (de petite taille).

Les signes cliniques observés sont sensiblement les mêmes que dans la maladie naturelle, de même les lésions. Cependant, dans la maladie expérimentale, il est noté dans 5 cas (sur 15) de la péritonite (purulente dans 3 cas) (1).

La réceptivité raciale des sujets est très importante ainsi qu'en témoigne le tableau suivant :

TABLEAU III

\begin{tabular}{|c|c|c|}
\hline INOCIJLÉS - 29 & RÉRACTAIRTS $=15$ & RLECPTIIS $=14$ \\
\hline Moutons maures: $8 \ldots$ & 8 & 0 \\
\hline Chèvres maures : $4 \ldots$ & 4 & 0 \\
\hline Chèvres sud & 3 & 14 \\
\hline
\end{tabular}

(1) Il faut cependant être prudent dans l'interprétation, car certaines peritonités sont d'origine traumatique. Le thermometre introduit brutalement dans le rectum des chèvres, 'sujets naturellement indociles, est souvent "l'agent causal » de semblables lésions.
Nous avons donnć plus haut notre opinion sur cette différence dé réceptivité. Il faut signaler cependant que la plupart des chèvres du sud étaient jeunes (six à douze mois) alors que les maures étaient adultes.

La période d'incubation est en moyenne de trois à quatre jours. La voie d'introduction du virus, intraveineuse ou sous-cutanée, ne semble pas avoir d'influence sur la durée de l'incubation ou l'évolution de la maladie.

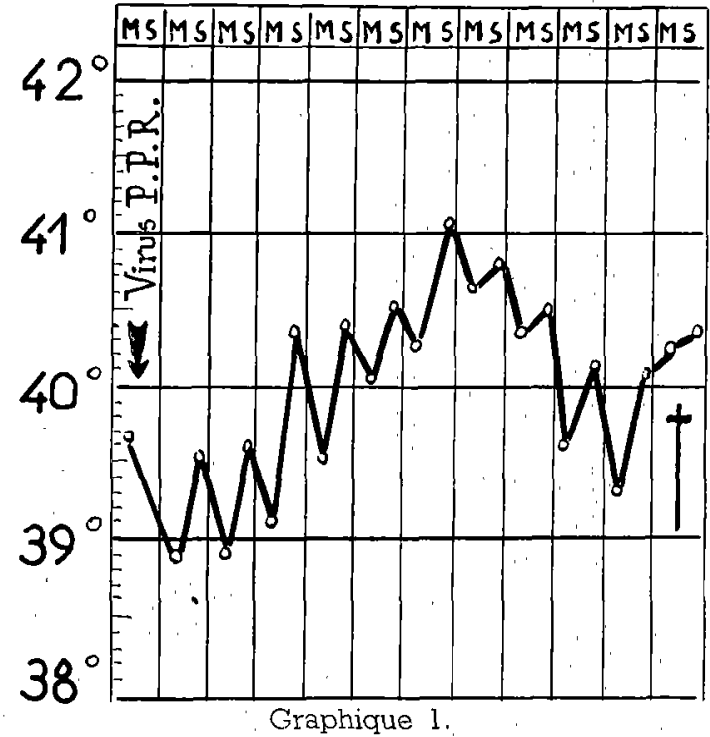

Chèvre 6: Infection expérimentale par viruis P:P.R.

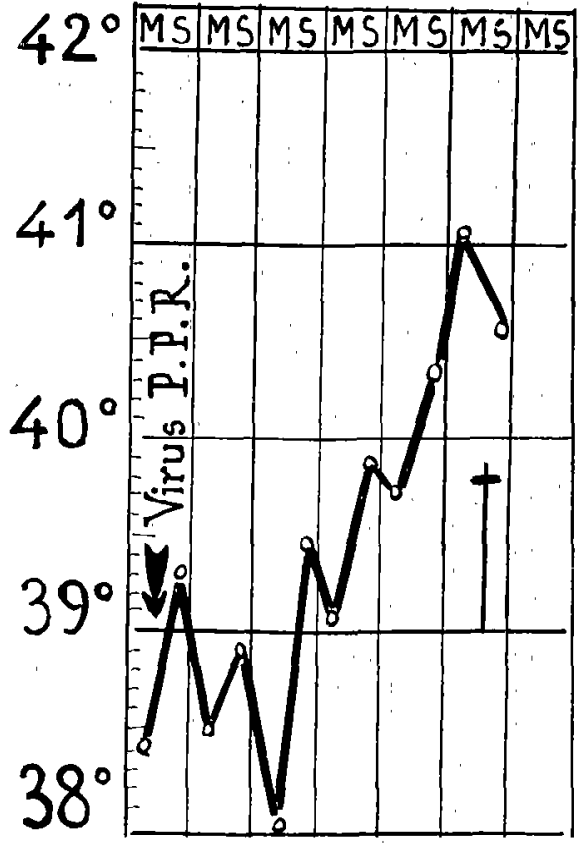

Graphique 2.

Chèvre 18 : Infection expérimentale par virus.P.P.R. 
L'infection est obtenue aussi bien avec le matériel virulent frais (sang) qu'avec le matériel lyophilise (rate + ganglions, ou rate + ganglions + cerveau)

Les moutons maures tenus comme réfractaires montrent fréquemment une poussée thermique, à l'acmé de laquelle on trouve des parasites endoglobulaires dans les frottis de sang : anaplasmes, piroplasmes, theileries. Il est probable que cette " sortie " d'hématozoaires est consécutive à l'intervention virale, dont les manifestations cliniques sont insignifiantes. voie endoveineuse $5 \mathrm{~cm}^{3}$ de sang virulent d'une chevre présentant les signes cliniques de la "Peste des petits ruminants ", souche Bouaké.

Ces cinq sujets ne réagissent pas alors qu'un témoin meurt dans les délais habituels.

Rapports entre le virus de la "Peste des petits ruminants " et le virus bovipestique.

Il est indéniable que l'aspect clinique des ovins et caprins atteints de "Peste des petits ruminants 》 est assez semblable à celui de la peste bovine chez

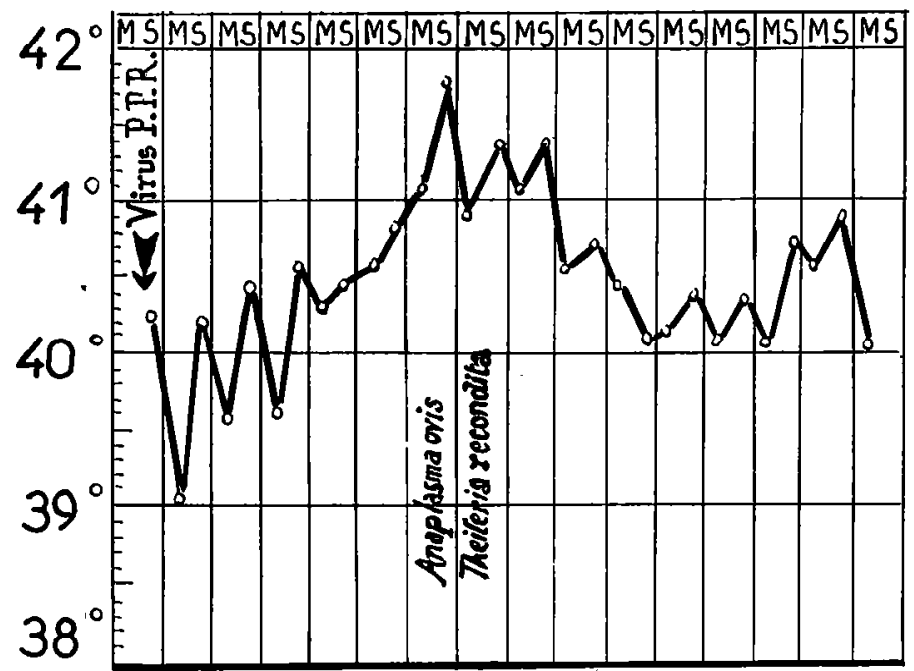

Graphique 3

Mouton Maure 6 : Infection expérimentale par virus P.P.R.

La sortie des hématozoaires coïncide avec la fin de la période d'incubation de la P.P.R.

\section{B. - Avec le virus Bouaké}

Cette souche a été isolée à Bouaké, le 20 ; 25 , d'un bouc infecté de la maladie naturelle à Korhogo (Côte-d'Ivoire).

Le matériel virulent est constitué par du sang, de la rate, des ganglions mésentériques reçus par avion à Dakar, le 23/2/55, et lyophilisés.

Les divers passages effectués sur des caprins n'apportent pas de faits nouveaux concernant l'évolution de la maladie.

Infection croisée entre le virus Kaolack et le virus Bouaké.

Il est intéressant de savoir si les souches Kaolack et Bouaké sont identiques, du moins quant à leur pouvoir infectant.

Pour cela, cinq chèvres guéries d'une infection expérimentale par la souche Kaolack reçoivent par les bovins. C'est ce qui incite les premiers observateurs (Cathou en particulier) à intervenir dans les foyers de "Peste des petits ruminants » avec le sérum antipestique bovin.

Les résultats sont prometteurs, ce qui renforce l'idée qu'il s'agit d'une affection apparentée à la peste bovine. Mais leur analyse ne résiste pas à la critique.

En effet, les expérimentateurs opèrent constamment dans les foyers, alors que les animaux sont soit malades, soit en incubation de la maladie soit contaminés. De sorte que les résultats apparemment favorables n'ont aucune signification. Les " guéris 》 constituent le pourcentage habituel de rescapés de la maladie évoluant naturellement.

Et d'ailleurs, le sérum antipestique a un pouvoir curatif très douteux et un pouvoir préventif faible. Il serait donc étonnant qu'un sérum antipestique bovin, injecté à des petits ruminants présentant 
une infection qui n'cst cortainoment pas la peste bovine typique (puisqu'elle n'est pas contagieuse naturellement pour les bovins sans bosse normalement très réceptifs au «typhus bovin»), ait une action prophylactique appréciable.

Il est un point cependant qui mérite d'être éclairci, c'est le comportement des veaux inoculés en premier lieu de virus «Peste des petits ruminants» puis recevant dans les quinze jours suivants le virus pestique bovin. Gargadennec et Lalanne écrivent (1942) : «L'injection de sang d'un animal malade à un veau neuf ne détermine pas l'apparition de la peste bovine. Ce même veau, qui reçoit 15 jours plus tard une injection de sang pestique virulent. fait une peste classique ». Bouvier (1954) écrit le contraire et ses expériences paraissent concluantes.

Nous répétons les mêmes expériences, qui confirment celles de Bouvier. En voici le résumé :

Sept veaux sans bosse reçoivent par voie endoveineuse $5 \mathrm{~cm}^{3}$ de sang de la chèvre $\mathrm{n}^{0} \mathrm{l}$ atteinte de «Peste des petits ruminants". Trois autres veaux servent de témoins.

Les veaux inoculés de virus «Peste des petits ruminants. » font une réaction thermique légère vers le $3^{\mathrm{c}}, 4^{\circ}$ ou $5^{\circ}$ jour 30 jours après l'injection de virus «Peste des petits ruminants », ils sont infectés par voie endoveineuse avec $5 \mathrm{~cm}^{3}$ de sang de veau atteint de pesto bovino. Ils no róagissont pas; par contre, les témoins font une réaction nette et deux sur trois meurent.

TABLEAU IV

\begin{tabular}{|c|c|c|c|}
\hline No VEAU & $\begin{array}{c}\text { REACTION } \\
\text { «peste des petits } \\
\text { ruminants 》 }\end{array}$ & $\begin{array}{l}\text { CONTROLE } \\
\text { virus } \\
\text { peste bovine }\end{array}$ & $\begin{array}{c}\text { OBSER- } \\
\text { VATIONS }\end{array}$ \\
\hline A & 0 & 1 & ' \\
\hline 3 & \pm & 0 & \\
\hline 11 & \pm & 0 & \\
\hline 15 & + & 0 & \\
\hline 19 & 0 & 0 & \\
\hline 20 & + & 0 & \\
\hline 35 & + & 0 & \\
\hline $\begin{array}{l}\text { 16, témoin } \\
Y \text {, témoin } \\
Z \text {, témoin }\end{array}$ & $\vdots$ & $\begin{array}{l}+ \\
+ \\
+\end{array}$ & $\begin{array}{l}\text { meurt } \\
\text { meurt } \\
\text { survit }\end{array}$ \\
\hline
\end{tabular}

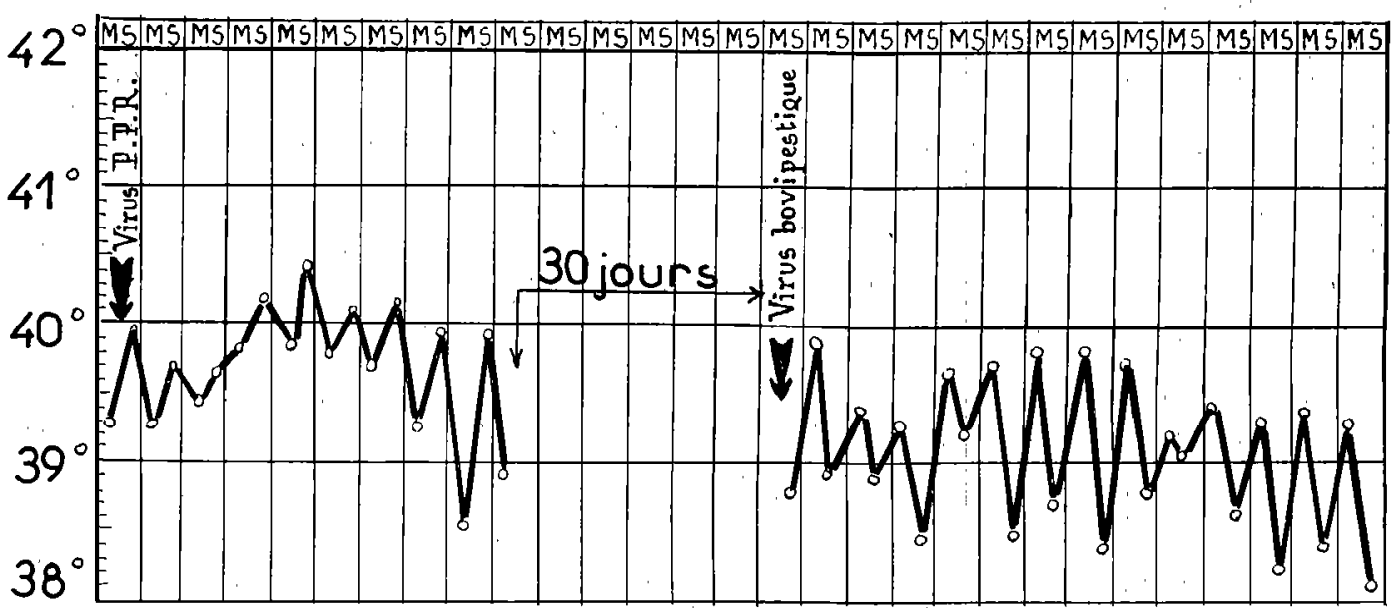

Graphique 4.

Veau 15 : Essai d'infection de bovin par virus P.P.R. Contrôle 'd'immunité par virus P.B. 


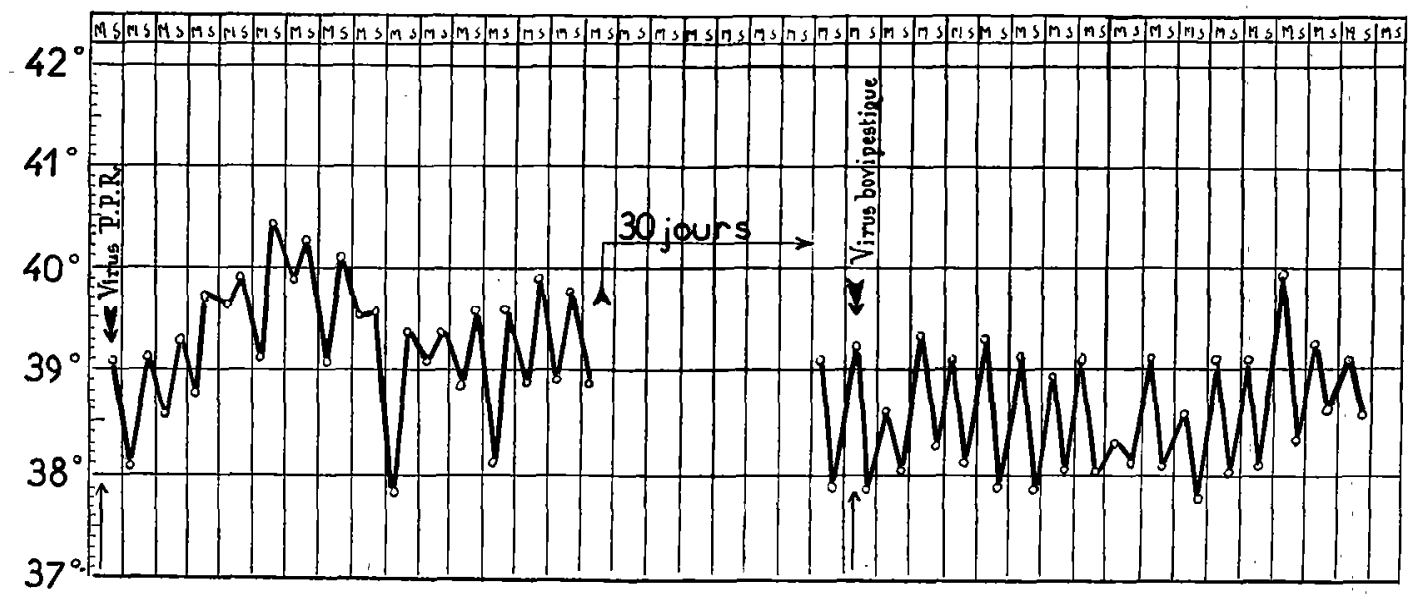

Graphique 5.

Veau 20 : Essai d'infection de bovin par virus P.P.R. Contrôle d'immunité par virus P.B.

\section{DEUXIEMME PARTIE}

\section{ÉTUDE EXPÉRIMEENTALE “ GUINÉE ”}

\section{BUT DE L'EXPÉRIENCE}

Les observations cliniques et les expériences antérieures (Gargadennec et Lalanne, Bouvier, 1954, Dakar, 1955) autorisent à penser que l'affection dite " peste des petits ruminants » (P.P.R.) est apparentée à la peste bovine (P.B.).

Pour contrôler cette hypothèse, il est décidé de pratiquer une expérimentation destinée à déterminer les parentés antigéniques entre les deux virus: P.P.R. et P.B.

Les épreuves prévues consistent en :

A) Epreuve de neutralisation du virus P.P.R. par le sérum anti-P.B.

B) Épreuves d'immunité croisée :

a) Chez le bœuf.

Virus P.P.R. puis virus P.B.

b) Chez la chèvre.

Virus P.B. puis virus P.P.R.

Virus vaccin-lapinisé contre P.B. puis P.P.R.

(Pour être complète, l'expérience devrait comporter : chèvres guéries de P.P.R. puis P.B.)

C) Enfin, il est recherché la possibilité d'immuniser la chèvre contre la P.P.R. en utilisant un virus homologue inactivé par le formol. (Vaccin de pulpes d'organes formolées).

$$
*
$$

Après deux essais infructueux tentés à Dakar (les chèvres achetées dans la région de Kaolack s'étant révélées contaminées avant toute inoculation), la région de Conakry (*) est choisie parce qu'elle présente divers avantages:

10 Aucun cas de peste bovine n'est signalé depuis de nombreuses années. Les animaux de cette région peuvent donc être considérés comme neufs. Quant à la peste des petits ruminants, elle y est inconnue.

$2^{\circ}$ L'élevage des bovins est inexistant dans cette région. Seules, quelques chèvres y vivent. Les risques de contamination accidentelle sont donc réduits.

$3^{\circ}$ Il est possible de se procurer assez facilement des animaux d'expérience (chèvres et veaux) dans les régions voisines (Kindia).

$4^{0}$ Deux parcs à bétail sont utilisables, distants l'un de l'autre de $6 \mathrm{~km}$.

$$
*^{*} *
$$

\section{A. - Nentralisation du virus P.P.R par le sérum contre la Peste bovine}

Cette épreuve s'est déroulée dans les conditions décrites au protocole (Annexe), le 9 mars 1956.

Les opérations ont été menées dans l'ordre indiqué et n'ont donné lieu à aucune observation particulière. Les résultats complets de l'expérience sont donnés dans les tableaux V, VI et VII (Annexe) et résumés ci-après (Tableau récapitulatif).

(*) Le lieu exact de l'expérience est Kabelé, situé à $36 \mathrm{~km}$ au nord de Conakry. 


\section{Observations générales.}

La symptomatologie observée chez les chèvres rćagissantes cst classique: ćlévation thermique, larmoiement et jetage séreux, puis mucopurulents et enfin franchement purulents.

La diarrhée est apparue sur la plupart des animaux infectés.

Les lésions buccales sont visibles à partir du $5^{\mathrm{e}}-6^{\mathrm{e}}$ jour suivant l'élévation thermique initiale.

L'avortement semble être de règle chez les fomelles gestanteș.

SÉRIE N (*).

Après l'inoculation du virus à différentes dilutions, additionné de sérum normal de bovin réceptif à la peste bovine, la plupart des animaux font une réaction fébrile, dont la précocité semble liée à la dose de virus inoculée.

Tròs rapidemont sont survenues des mortalités dans l'effectif.

Au $6{ }^{\mathrm{e}}$ jour après inoculation :

- 1 chèvre inoculée à la dilution 10-1.

- 1 chèvre inoculée à la dilution 10-2.

- 1 chèvre inoculée à la dilution $10-3$.

sont trouvées mortes. 'L'une (no 1.111) présente, outre des lésions de P.P.R. (érosions buccales, enduit pultacé et ulcérations du pharynx, lésions de la valvule iléo-cæecale), un phlegmon important au point d'inoculation, et des lésions septicémiques (pétéchies sur le cœur, foie dégénéré). Ces lésions septicémiques sont retrouvées sur nombre de chèvres ayant succombé les jours suivants ( $n^{\circ} 1.114$, $1.116,1.117,1.121,1.132)$. Ces lésions n'ayant pas été observées chez les animaux de la série $A$, il faut incriminer le sérum de bovin normal prélevé sur place, dans des conditions défavorables.

Cependant, il est indiscutable que sont relevées, à l'autopsie, les lésions concomitantes de peste des petits ruminants : érosions buccales, enduit pultacé et ulcérations du pharynx, suppuration des amygdales. Par ailleurs, il est à remarquer qu'aucune mort n'est imputable exclusivement à un processus septicémique.

Les lésions buccales sont apparues en général au $6 \mathrm{e}$ jour suivant l'inoculation. Toụs les animaux ayant présenté une réaction thermique, de type P.P.R. en sont porteurs au $7^{\mathrm{e}}$ jour' (16 mars).

La chèvre 1.147, inoculee à la dilution 10-6, avorte 5 jours après inoculation, soit le 14 mars, jour de l'élévation thermique. Le 18 mars, plusieurs chèvres gestantes de "cette série avortent (n० 1.136, 1.137, 1.138, dilution $10^{-5}$ ).

(*) Chèvres inoculées avec le mélange : virus P.P.R. + sérum normal bovin.
Enfin, la plupart des chèvres autopsiées montrent des lésions de pneumonie localisées à un lobe pulmonaire, ou à un lobule.

SÉRIE' $A\left({ }^{*}\right)$.

Trois morts seulement sont à signaler:

Bouc no 1.153, mort le 15 mars, sans avoir présenté d'élévation thermique. On note cependant une congestion des gencives et du pharynx et une congestion intestinale diffuse. La mort semble due à une pneumonie purulente.

Bouc no 1.176, mort le 13 mars. N'a présenté aucune élévation thermique. La mort est due à une pneumonie.

Chèvre no 1.185, morte le 17 mars. Aucun signe de P.P.R. La mort est due à une pneumonie:

Par ailleurs, seuls ont réagi quatre animaux du groupe $10^{-1}$ et deux animaux du groupe 10-2.

Une réaction aberrante est survenue dans le groupe 10-4. Elle est liée vraisemblablement à la présence dans l'inoculum d'une particule virulente suffisamment importante pour provoquer l'infection. Le produit inoculé n'est pas, en effet, une solution parfaite où les molécules sont réparties en nombre proportionnel à la dilution, mais une suspension constituée de particules virulentes plus ou moins volumineuses. L'une de celles-ci a pu être transportée à travers la dilution $10^{-3}$ et se retrouver dans la dilution $10-4$. Si cette particule était de taille suffisante, l'action du'sérum n'a pu être assez marquée pour neutraliser le virus.

Dans l'ensemble, les réactions observées sont beaucoup moins fortes que dans la serie $N$.

Cependant, à la date du 17 mars, soit huit jours après l'inoculation, une seule chèvre montre des lésions buccales nettes, bien qu'à la dilution 10-1 certaines réactions thermiques soient précoces (no $1: 151 ; 1.152,1.157$ ).

\section{Discussion des résultats.}

L'examen du tableau récapitulatif montre que le nombre de réagissants est nettement inférieur dans la série $A$ : on n'observe en effet que deux réagissants dans le groupe 10-2, et aucun dans le groupe 10-3. Par contre, dans la série $\mathrm{N}$, on compte encore quatre animaux infectés à la dilution 10-5.

L'analyse statistique des résultats ne peut être réalisée par les méthodes habituelles (méthode de Reed et Muench). En effet, ni dans la série $N$, ni dans la série $A$, la dilution critique (donnant approximativement $50 \%$ de réaction) n'est encadrée par. deux dilutions' inférieures et deux dilutions supé-. rieures. Cependant, l'analyse globale des résultats

$\left(^{*}\right)$ Chèvres inoculées avec le mélange : virus P.P.R. + Sérum antibovipestique. 
TABLEAU RÉCAPITULATIF

\begin{tabular}{|c|c|c|c|c|}
\hline \multirow[t]{2}{*}{ DLUTION } & \multicolumn{2}{|c|}{$\begin{aligned} & \text { SÉRIE N } \\
= & \text { vinus P.P.R. } \\
+ & \text { sérum normal }\end{aligned}$} & \multicolumn{2}{|c|}{$\begin{aligned} & \text { SÉRIE } A \\
= & \text { virus P.P.R. } \\
& + \text { Sérum } \\
\text { antibovipestique } & \end{aligned}$} \\
\hline & + & - & + & 一 \\
\hline $10-1$ & 6 & 0 & 4 & 2 \\
\hline $10-2$ & 6 & 0 & 2 & 4 \\
\hline $10-3$ & 5 & 1 & 0 & 6 \\
\hline $10-4$ & 5 & 1 & 1 & 5 \\
\hline $10-5$ & 4 & 2 & 0 & 6 \\
\hline $10-6$ & 2 & 4 & 0 & 6 \\
\hline
\end{tabular}

montre que le sérum contre la peste bovine possède un pouvoir neutralisant certain.

On peut donc conclure que le virus de la peste des petits ruminants est antigéniquement identique à celui de la peste bovine.

\section{B. - Épreuves d'immunité croisée}

a) Épreuve d'immunité croisée virus P.P.R.virus Peste bovine chez le veau.

Le 2 mars 1956, six veaux no $1.102,1.103,1.106$, $1.107,1.109,1.110$, sont inoculés, chacun avec $10 \mathrm{~cm}^{3}$ d'une suspension d'organes de chèvres infectées de P.P.R. (passage préliminaire des souches souche Bouaké).

Ces veaux sont placés à l'attache sous un hangar en paille, en compagnie des chèvres inoculées de P.P.R. (premier passage).

A la suite de l'inoculation, il n'est pas constaté d'élévation thermique notable.

Cependant, les veaux no 1.103, 1.106 présentent au $6 \mathrm{e}$ jour après inoculation du larmoiement. Au $8 \mathrm{e}$ jour, le veau $\mathrm{n}^{0} 1.106$ montre des érosions buccales nettes. Cet animal s'affaiblit, entre en agonie au 11 e jour et meurt. Autopsié immédiatement, i1 présente les lésions suivantes : très mauvais état général, légères ulcérations de la muqueuse buccale, ulcérations nécrotiques du pharynx, légère inflammation du larynx, inflammation hémorragique de la caillette et de la valvule iléo-cæcale, légère inflammation du cæcum, entérite diffuse du grêle.

Des prélèvements histologiques sont effectués et seront ultérieurement examinés.

Au $13^{\mathrm{e}}$ jour, le veau no 1.103 est sacrifié in extremis.

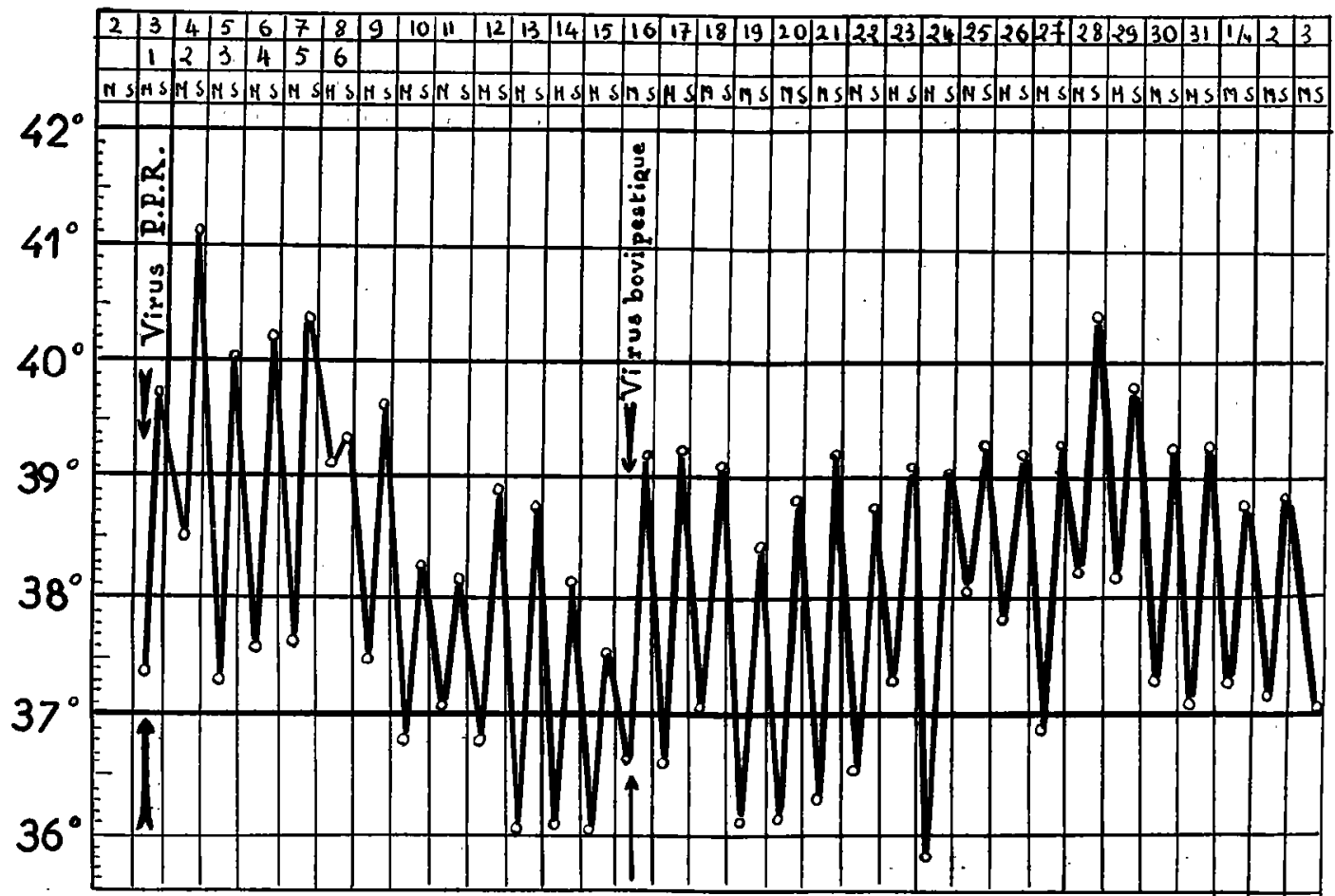

Graphique 6.

Veà 1.102 : Essai d'infection de bovin avec virus P.P.R. Contrôle d'immunité avec P.B: 
L'autopsie permet de conclure à une mort par épuisement en état de misère physiologique. Aucune lésion particulière n'est observée.

Les quatre autres veaux sont inoculés le 16 mars, ainsi que deux veaux neufs témoins, $n^{0} \cdot 1.101$ et 1.105, avec une suspension d'organes infectés de peste bovine (origine Saint-Louis, Bamako et Conakry, premier passage).

Les quatre veaux inoculés de P.P.R. résistent parfaitement à l'épreuve par le virus pestique bovin, qui tue les témoins en huit jours.

\section{Conclusion.}

Dans les conditions de cette expérience, le virus P.P.R. protège le boeuf contre une inoculation ultérieure de virus bovipestique.

b) Épreuves d'immunitè croisée, chez la chèvre.

10 Peste bovine, P.P.R.

Le 10 mars 1956, une suspension composée de sang virulent (Bamako), rate et ganglions (SaintLouis), rate et ganglions (Conakry) est préparée, décantée. On inocule $4 . \mathrm{cm}^{3}$ par voie sous-cutanée à chacune des 12 chèvres $n^{0} 1.203,1.204,1.205$, $1.206,1.207,1.208,1.209,1.210,1.211,1.212,1.213$, $1.214,1.215$.

Les températures sont prises matin et soir.

Cinq jours plus tard, quatre chèvres ( $\mathrm{n}^{0}$ 1.203, $1.205,1.207,1.208$ ) sont trouvées mortes. A l'autopsie, la putréfaction étant déjà installée, il est seulement possible de constater la présence d'érosions buccales, nettes.

Parmi ces animaux, seuls les no 1.205 el 1.207 avaient accusé une réaction thermique légère.

Le 17, soit au septième jour après inoculation, les chèvres'1.206, 1.211 et 1.213 meurent. L'autopsie immédiatement pratiquée permet d'observer d'importantes érosions de la muqueuse buccale avec enduit pultacé, des ulcérations au niveau du pharynx et une congestion de la valvule iléo-cæcale.

La chèvre: 1.211 présente de la péricardite, de la pneumonie et une péritonite (non traumatique).

Ce même jour, sont sacrifiées les chèvres no 1.210 et 1.215, offrant une courbe thermique ascendante. A l'autopsie, aucune lésion caractéristique, sauf une congestion de la muqueuse gingivale.

La chèvre 1.212 meurt le 18 mars. A l'autopsie, on note la présence d'érosions buccales, d'uleérations au niveau du pharynx, de la congestion de la valvule iléo-cæcale et de l'intestin, ainsi que des lésions de pneumonie.

Les chèvres 1.204 et 1.209 meurent le 19 mars.

Toutes deux présentent des érosions buccales, des ulcérations du pharynx, une congestion de la valvule iléo-cæcale.

\section{Conclusion,}

L'épreuve d'inoculation de virus P.P.R. ne peut être pratiquée faute d'animaux ayant résisté à l'inoculation de peste bovine.

Les chèvres de Guinée sont donc très réceptives au virus de la peste bovine, qui ne provoque chez elles qu'une réaction thermique modérée, mais entraîne l'apparition de signes cliniques graves: larmoiement, jetage, érosions de la muqueuse buccale, La mort survient dans un bref délai : sept à huit jours après inoculation.

La réceptivité des chèvres de Guinée à la peste bovine est un élément nouveau qui devra être contrôlé.

$2^{\circ}$ Épreuve d'immunité croisée virus-vaccin bovipestique lapinisé - virus P.P.R.

Le 10 mars 1956, les 12 chèvres du lot no 3 reçoivent chacune, par voie sous-cutanée, une dose de $4 \mathrm{mg}$ de virus bovipestique lapinisé (organes secs).

Les températures sont prises matin et soir pendant les huit premiers jours et seulement le matin les jours suivants.

A la suite de l'inoculation, aucune élévation thermique caractéristique n'est observée.

Cinq chèvres meurent avant l'épreuve :'

No 1.214, morte 14 jours après inoculation. Températures matinales régulières (37 ${ }^{\circ}$ ). Meurt le 24 ,mars. A l'autopsie : lésions de pneumonie.

No 1.216, morte 6 jours après inoculation : pneumonie.

No 1.219, meurt 10 jours après inoculation : bronchopneumonie.

No 1.220 , montre une réaction thermique assez nette après inoculation. Meurt ' 10 ljours après inoculation : broncho-pneumonie.

No 1.221, meurt 13 jours après inoculation : bronchopneumonie.

Quatorze jours après inoculation, les chèvres survivantes reçoivent une suspension d'organes de chèvres infectées de P.P.R. A la suite de cette inoculation d'épreuve, la plupart des chèvres montrent une courbe thermique ascendante. Cependant, les températures restent bien inférieures à celles qu'on observe dans la P.P.R.

Deux chèvres meurent :

$N^{\circ} 1.227$, meurt 6 jours après infection et réáction thermique modérée. Autopsie : congestion de la muqueuse buccale. Bronchopneumonie. 
No 1.222 , meurt 7 ours après infection, en ayant montré une réaction thermique modérée. A l'autopsie : congestion de la muqueuse buccale, congestion de la valvule iléocæcale, lésions de broncho-pneumonie.

Cinq autres chèvres survivent 10 jours après inoculation d'épreuve :

No 1.217, réaction thermique modérée. Pas de signes cliniques.

No 1.224, même observations.

No 1.225, mêmes observations.

No 1.226, réaction thermique à peine perceptible.

\section{Conclusion.}

Il semble que l'inoculation de virus-vaccin bovipestique lapinisé soit bien tolérée et protège une partie des sujets contre une inoculation ultérieure de virus P.P.R.

c) Essai d'immunisation des chèvres contre la P.P.R. à l'aide de virus homologue inactivé.

Le 26 mars 1956, on prépare du vaccin formolé contre la P.P.R. de la manière suivante : des organes (rate et ganglions) de chèvres, infectées lors du passage préliminaire des souches, sont broyés aseptiquement.

A une partie de pulpe $(100 \mathrm{~g})$, on ajoute 3 parties $\left(300 \mathrm{~cm}^{3}\right)$ d'eau physiologique formolée à $6 \%$.

Le tout est placé dans un flacon et agité. Le flacon est laissé 48 heures à la température ambiante, agité plusieurs fois par jour. Il est ensuite conservé au réfrigérateur jusqu'à l'emploi.

Le 10 mars 1956, on injecte $10 \mathrm{~cm}^{3}$ de vaccin à chacune des chères d'un lot de 12.

Les températures sont prises matin et soir. Aucune variation n'est observée.

Six chèvres meurent avant épreuve :

No 1.189 , morte 11 jours après vaccination : bronchopneumonie.

No 1.190 , morte 12 jours après vaccination : bronchopneumonie.

No 1.191 ; morte 8 jours après vaccinảtion : bronchopneumonie.

No 1.192, morte 8 jours après vaccination : bronchopneumonie.

No 1.201, morte 6 jours après vaccination : bronchopneumonie.

No 1.202 , morte 9 jours après vaccination : bronchopneumonie:

Les six suivantes reçoivent 14 jours après vaccination une suspension d'organes virulents par voie sous-cutanée.
Cette épreuve est suivie; chez tous les animaux, d'une rapide et importante ascension thermique. Les températures matinales dépassent $40^{\circ} \mathrm{chez}$ deux chèvres, dont l'une (no 1.193) meurt 11 jours après l'épreuve. $\AA$ l'autopsie, on note : congestion de la muqueuse buccale et lésions de bronchopneumonie.

Cependant, 10 jours après l'épreuve, cinq chèvres survivent et une seule d'entre elles montre une congestion de la muqueuse buccale. Leur température tend à redevenir normale.

\section{Conclusion.}

Il semble que le vaccin formolé ait conféré aux chèvres un certain degré de résistance à l'affection. Cependant, les animaux éprouvés ont fortement réagi, et il ne saurait être question de les considerer comme immunisés de façon satisfaisante.

\section{DISCUSSION GÉNÉRALE DES RÉSULTATS}

Il est indéniable que certains points de l'épizootologie de la P.P.R. restent obscurs et que l'étude expérimentale est incomplète.

Les recherches ultérieures devront porter sur :

- la réceptivité des chèvres du sud et particulièrement de la Guinée au virus bovipestique; - le comportement des chèvres guéries de P.P.R. a la suite de l'inoculation de virus bovipestique; - les tests sérologiques : réaction de fixation du complément et séro-neutralisation. En ce qui concerme la séro-neutralisation, la technique est à réviser pour permettre une meilleure appréciation statistique.

Une étude immunologique et sérologique des divcrs virus pestiques apparentés ou modifiés est à envisager : virus P.B., virus P.P.R., virus P.B. caprinisé, virus P.B. lapinisé, virus P.B. avianisé.

L'immunisation contre la P.P.R. est à mettre au point soit par la préparation d'un vaccin tissulaire inactivé, soit par l'emploi judicieux de virus-vaccins apparentés (virus-vaccin bovipestique caprinisé ou lapinisé ou avianisé), soit, enfin, par l'adaptation et la fixation du virus P.P.R. sur un animal de laboratoire.

Mais, dès maintenant, certains points sont bien établis :

- le virus P.P.R. est apparenté au virus P.B. car l'affection qu'il provoque chez les caprins est très voisine de la peste bovine des bovins ; les signes cliniques sont superposables, de même les lésions macroscopiques et microscopiques ;

- la neutralisation du virus P.P.R. par le sérum bovipestique est positive ;

- l'expérience consistant a infecter des bovins avec du virus P.P.R. puis à contrôler leur résistance au virus P.B. donne régulièrement les mêmes 
résultats : les bovins ne semblent pas influencés par le virus P.P.R., ou à peine (faible réaction thermique) mais s'avèrent ensuite réfractaires à l'inoculation de virus $P$. B.

Cet ensemble de facteurs nous amène à penser que le virus P.P.R. est une variante du virus P.B. Il reste à caractériser cette variante de façon plus précise.

Mais alors se pose la question de l'origine de ce virus. Est-ce un virus "sauvage » P.B. adapté naturellement et accidentellement sur caprins? Est-ce un virus-vaccin caprinisé ou lapinisé, ayant servi à l'immunisation des bovins, qui s'est fixé sur caprins en se modifiant? Nous n'avons pu encore nous faire une opinion.

Nous avons signalé que ce virus P.P.R. n'était pas naturellement infectant pour le boeuf. Mais nos observations ne sont pas encore assez nombreuses pour être définitives.

Conclusion. - Le virus de la peste des petits ruminants et le virus de la peste bovine ayant des relations antigéniques très proches, le problème de la prophylaxie de la peste bovine risque de devenir plus complexe et plus difficile à résoudre que les progrès récents de la prophylaxie de cette maladie ne le laissaient supposer.

La virulence du premier peut en effet s'exacerber pour le boeuf sous l'influence des facteurs intervenant habituellement : souche spécialement pathogène, réceptivité particulière de certains sujets...

Ent out cas, la permanence d'un virus « pestique » chez les petits ruminants vivant au contact de bovins particulièrement sensibles à la peste bovine constitue un risque "potentiel » qu'on ne doit pas sous-estimer.

(Travail du laboratoire fédéral de l'élevage, "G. CURASSON " à Dakar. Directeur : P. Mornet).

\section{BIBLIOGRAPHIE}

GARGADENNEC (L.) et LALANNE (A.). - La peste des petits ruminants. Bull. Serv. Zoo, A.O.F. (1942), 5, 16.

CURASSON (G.).- Traité de Pathologie exatique vétérinaire et comparée (p. $35,45,81$ ). Vigot Frères Édit. Paris, 1942.

MORNET (P.). - Prophylaxie médicale de la peste bovine en Ifrique Occidentale Française. Bull. Serv. Élevage A.O.F. (1948), 1, 8.

BOUVIER. - Rapport sur la Peste des petits ruminants en Côte-d'Ivoire (1954).

Rapports annuels Côte-d'Ivoire (1940-1954). Rapports annuels Dahomey (1941-1954).

JACOB $\left(F_{1}\right)$. - Les bactéries lysogènes et la notion de provirus. Masson et Cie, Édit., Paris, 1954.

HAUDUROY $\left(P_{.}\right)$. - Problèmes actuels de virologie. Masson et Cie, Édit., Paris, 1954.

RAMON (G.). - Porteurs et vecteurs de germes microbiens. Bull. Off. Int. Epiz. (1956), 45, 8.

MORNET (P.), ORUE (J.) et GILBERT (Y.). — Unicité et plasticité du virus bovipestique. $\mathbf{A}$ propos d'un virus naturel adapté sur petits ruminants. C. R. Acad. Sciences (1956), 242, 2886-2889.

\section{SUMMARY}

The «Peste des petits ruminants 》 in French West Africa

The disease which was recorded for the first time in 1940 in the Ivory Coast, is similar to rinderpest as far as epizootiology, clinical signs, pathology, and immunity are concerned. It is sporadic or enzootic every year in the Ivory Coast, Dahomey and Southern Provinces of Senegal.

The infection is not transmitted naturally to cattle but, if inoculated with the virus, the animals become immune to subsequent challenge with bovine rinderpest virus.

It has been shown that the "peste des petits ruminants 》 virus and bovine rinderpest virus have a very close antigenic relationship. The increasing incidence of the disease may make prophylaxis of rinderpest more complex and difficult. 


\section{RESUMEN}

\section{La « Peste de los pequeños rumiantes » en Africa Occidental Francesa}

La peste de los pequeños rumiantes, señalada por primera vez en 1940 en Costa de Marfil, es una afección comparable a la peste bovina por sus caracteres epizoóticos, clinicos, anatomopatológicos e inmunológicos. Se manifiesta cada año de manera esporádica o enzootica en Costa de Marfil, Dahomey y en la región del sur del Senegal.

Esta afección no es naturalmente contagiosa para los bovinos. Los animales de esta raza a los que se les ha inoculado el virus, 'se hacen refractarios a la inoculación ulterior del virus peste bovina.

El experimento demuestra que el virus de la peste de los pequeños rumiantes y el virus peste bovina tienen relaciones antigénicas muy cercanas. El problema de la profilaxis de la peste bovina se hace más complejo y más dificil de resolver con la aparición y el desarrollo de esta nueva afección.

\section{ANNEXE}

\section{PROTOCOLE EXPÉRIMENTAL}

Souches de virus.

\section{A. - Matéxiel ntilisé}

a) Virus P.P.R. : deux souches sont conservées à Dakar :

- Souche Kaolack (2 lots).

- Souche Bouaké (2 lots).

Un test préliminaire de ces souches permettra de déterminer celle à utiliser.

b) Virus Peste bovine.

Sérums pour neutralisation.

a) Sérum antibovipestique.

b) Sérum normal de bovin réceptif à la peste bovine.

Animaux.

a) Chèvres, pour :

Nombre

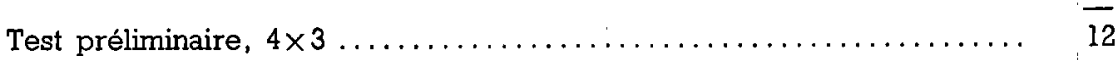

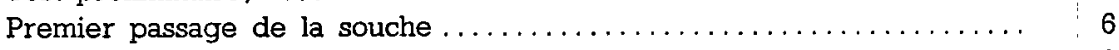

Neutralisation $d u$ virus. $\ldots \ldots \ldots \ldots \ldots \ldots \ldots \ldots \ldots \ldots \ldots, 72$

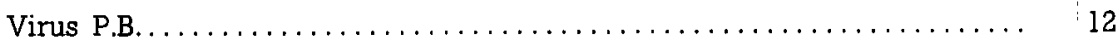

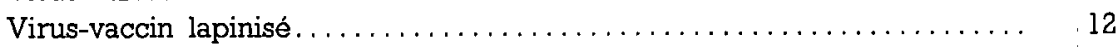

Vaccin tissulaire inactivé (formolé) $\ldots \ldots \ldots \ldots \ldots \ldots \ldots \ldots \ldots \ldots, 12$

b) Veaux :

Nombre

Passage Peste bovine $\ldots \ldots \ldots \ldots \ldots \ldots \ldots \ldots \ldots \ldots \ldots \ldots \ldots \ldots, \frac{\overline{2}}{2}$

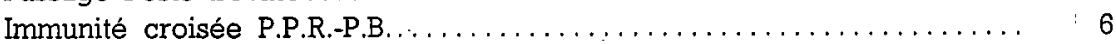

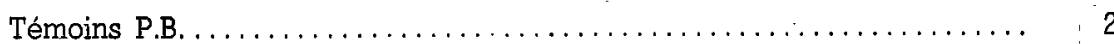

Total..... 10 


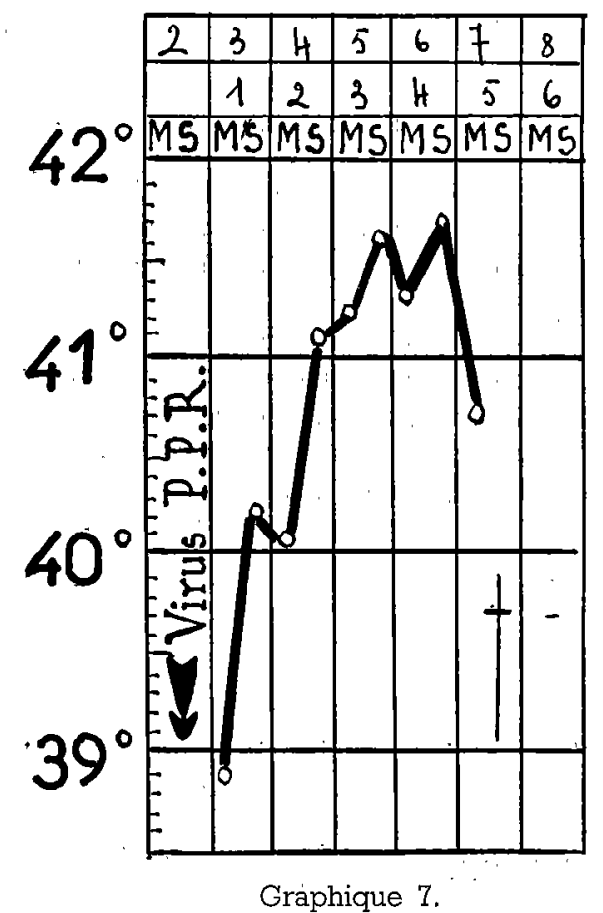

Bouc 1.142: 1 er passage de la souche P.P.R.

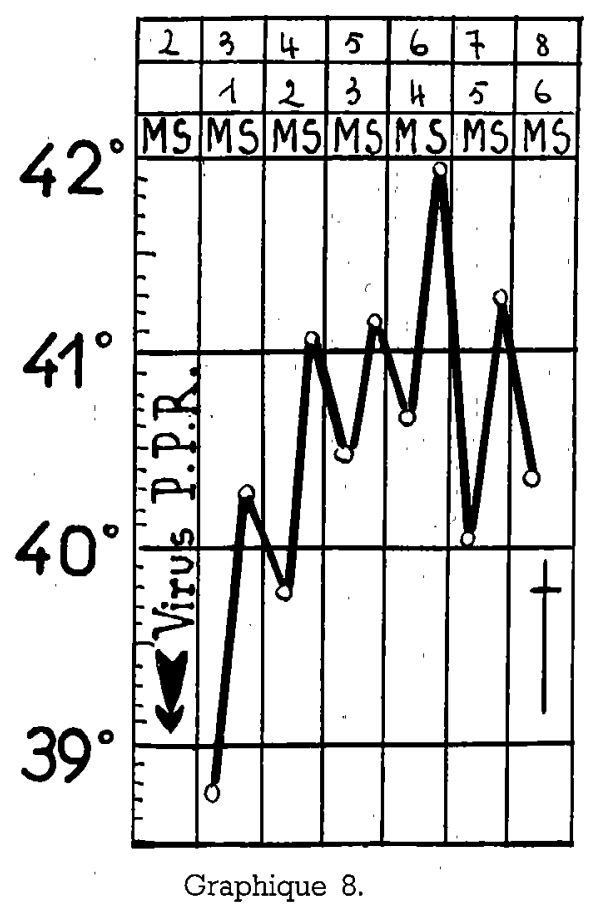

Bouc 1.171 : ler passage de la souche P.P.R.

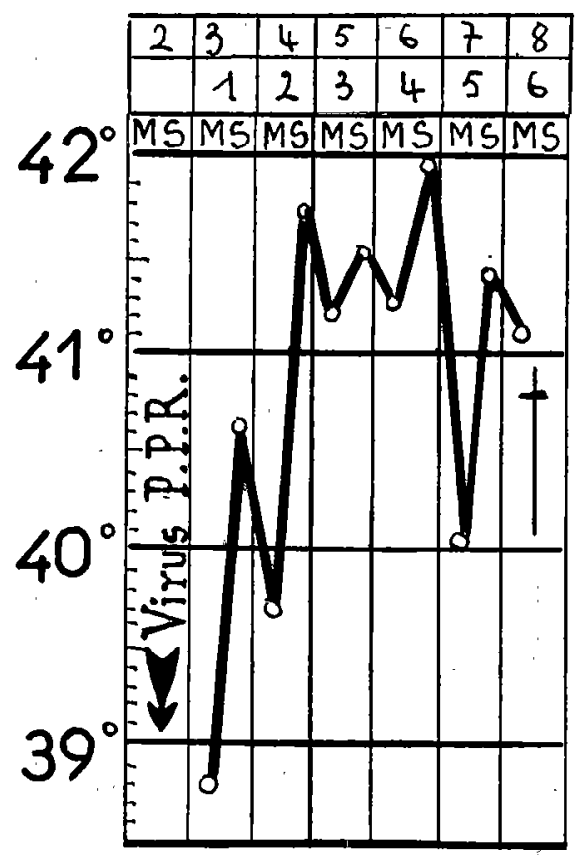

Graphique 9.

Bouc $1.173: l^{\text {er }}$ passage de la souche P.P.R. 


\section{B. - Expérimentation proprement dite}

10 Test préliminaire des souches de P.P.R.

Parmi les lots de virus P.P.R. lyophilisé conservés à Dakar, quatre sont testés :

Lot provenant de la chevre 19 ,

Lot provenant de la chèvre 28$\}$ virus P.P.R. souche Kaolack.

$\left.\begin{array}{l}\text { Lot provenant de la chèvre } 24 \\ \text { Lot provenant d'un bouc Bouaké }\end{array}\right\}$ souche Bouaké.

10 Lot 19 .

Inoculé aux chèvres nos $1,2,3$.

Réaction thermique tardive vers le $11^{\theta}$ et $12^{\mathrm{e}}$ jour.

$\mathrm{Ce}$ lot est éliminé.

2o Lot 28.

Inoculé aux chèvres nos $4,5,6$.

Réaction thermique nette au $3^{\circ}$ jour, dépassant $40^{\circ}$ le matin.

3o Lot Bouaké.

Inoculé aux chèvres nos $7,8,9$.

Réaction thermique nette dès le $3^{\theta}$ jour après inoculation.

Les chèvres sont abattues et leurs organes conservés à $-20^{\circ}$ pour inoculations ultérieures.

$4^{\circ}$ Lot 24.

Inoculé aux chèvres $n^{08} 10,11,12$.

Réaction assez nette de la chèvre 10, abattue 6 jours plus tard en présentant les signes nécropsiques de Peste des petits ruminants.

Les chèvres 11 et 12 ont réagi bien plus tardivement.

Ces divers résultats nous ont amenés à décider que les organes des chèvres $7,8,9$ serviraient aux inoculations ultérieures.

\section{$2^{\circ}$ Passage de la souche P.P.R.}

Le 2 mars 1956, cinq boucs et une chèvre reçoivent une suspension de rate et ganglions des chèvres précédemment sacrifiées après avoir reçu du virus lyophilisé (souche Bouaké). L'inoculation a lieu par voies sous-cutanée et intraveineuse.

Ces animaux, qui portent les numéros 1.142, 1.171, 1.173, 1.187, 1.198, 1.200, sont placés en compagnie des veaux inoculés de Peste des petits ruminants sous un hangar en paille. Leur température est prise matin et soir.

Ces six animaux font des courbes thermiques ascendantes; dans cinq cas, la température dépasse $41^{\circ}$ au matin du $3^{e}$ jour après l'inoculation.

No 1.142. Température :

$41,2^{\circ}$ au matin du $3^{e}$ jour après inoculation.

$41,3^{\circ}$ le lendemain matin.

$40,7^{\circ}$ le jour suivant. On constate de la diarrhée. L'animal est abattu le 7 mars. On note à l'autopsie la présence de lésions buccales, et d'ulcérations pharyngées. Rate et ganglions sont prólevés et placés au conservateur à - 200.

No 1.198. Température :

$41,9^{\circ}$ au matin du $3^{\ominus}$ jour suivant l'inoculation.

$40,9^{\circ}$ le lendemain matin.

$40,3^{\circ}$ le jour suivant. On note jetage, diarrhée et lésions buccales. Animal abattu le 7 mars. Autopsie : érosions buccales, ulcérations du pharynx. Rate et ganglions sont prélevés et placés au conservateur.

No 1.200. Température :

$41,8^{\circ}$ au matin du $3^{e}$ jour suivant l'inoculation.

$41,4^{\circ}$ le lendemain matin.

$40,1^{\circ}$ le jour suivant. L'animal est abattu le 7 mars. A l'autopsie, pas de lésions. 
No 1.171 Temperature :

$40,5^{\circ}$ au matin du $3^{e}$ jour après inoculation.

$40,7^{\circ}$ le lendemain.

$40^{\circ}$ le jour suivant. Jetage et érosions buccales.

$40,4^{\circ}$ le 8 mars. L'animal est sacrifié. A l'autopsie : lésions buccales et pharyngées ; valvule iléocæcale congestionnée. Rate et ganglions sont prélevés et placés au conservateur.

No 1.173. Température :

$41,2^{\circ}$ au matin du $3^{e}$ jour après inoculation.

$41,2^{\circ}$ le lendemain matin.

$40^{\circ}$ le jour suivant.

$41,1^{\circ}$ le 8 mars. L'animal est abattu. On observe les mêmes lésions que chez la chèvre no 1.171 . Rate et ganglions sont prélevés et placés au conservateur.

No 1.187. Température :

$41,5^{\circ}$ au matin du $3^{e}$ jour après inoculation.

$41,5^{\circ}$ le lendemain matin.

$40,7^{\circ}$ le jour suivant. Des érosions buccales apparaissent.

$40,3^{\circ}$ le 8 mars. L'animal est abattu. On observe les mêmes lésions que chez la chèvre n' 1.171 . Rate et ganglions sont prélevés et placés au conservateur.

Remarque : Le virus lyophilisé à $-30^{\circ}$ pendant plusieurs mois garde ses propriétés infectantes. Il reprend ses propriétés originales dès le ler passage sur animal.

\section{$3^{\circ}$ Passage de la souche de peste bovine.}

Le 2 mars 1956, du sang est obtenu des veaux n 1.104 et 1.108. Il estrecueilli dans un potà saignée qu'on place en glacière après coagulation. L'exsudat servira de sérum normal pour l'épreuve de séroneutralisation du virus P.P.R.

Ces deux veaux sont ensuite inoculés à l'aide d'une suspension d'organes de veaux infectés de peste bovine (souches Saint-Louis, Bamako et Kaolack lyophilisées).

Ces veaux sont isolés et un personnel spécial leur est affecté. Is montrent une courbe thermique régulièrement ascendante.

Au $7^{\text {e }}$ jour suivant l'inoculation, le veau $n^{\circ} 1.108$ présente du larmoiement, des lésions buccales et de la diarrhée. Il est sacrifié et ses organos sont prélovès.

Le veau $n^{\circ} 1.104$ montre les mêmes signes au $8^{e}$ jour. Il est sacrifié. L'autopsie montre les lésions habituelles de la peste bovine.

4. Séro-neutralisation du virus de la Peste des petits ruminants par le sérum contre la Peste bovine.

Cette épreuve consiste à rechercher l'influence du sérum contre la Peste bovine sur le pouvoir infectant du virus de la P.P.R.

\section{Matériel.}

Douze lots de 6 chèvres réceptives.

Virus P.P.R. (constitué par les organes des chèvres n $1.142,1.198,1.173,1.172$ et 1.187) scuche Bouaké, $1^{\text {er }}$ passage.

Sérum contre la peste bovine : fourni par le laboratoire de Saint-Louis (Sénégal).

Sérum de bovin neuf à la peste bovine (prélevé sur place sur des veaux qui, inoculés ensuite avec le virus de la peste bovine, ont fait une maladie typique):

\section{Réalisation.}

Les chèvres sont parquées dans le parc à bétail proche du Km 36. Elles sont réparties en douze lots de six chèvres, formant deux groupes de six lots. L'un des groupes est dénommé A (sujets destinés à recevoir virus P.P.R. + sérum antibovipestique), l'autre $N$ (sujets destinés à recevoir virus P.P.R. + sérum normal bovin).

Dans chacun des groupes $A$ et $N$, les lots sont numérotés de 1 à 6 .

Les organes prélevés sur les chèvres infectées de virus $l^{\text {er }}$ passage P.P.R. sont broyés stérilement. 
On pèse $50 \mathrm{~g}$ de cette pulpe, qu'on porte dans le bol stérile d'un Waring Blendor réfrigéré. On ajoute $200 \mathrm{~cm}^{3}$ d'un diluant constitué par $2 \%$ de sérum de cheval inactivé, dans une solution à $8.5 \%$ de chlorure de sodium. Après broyage pendant 5 minutes, on obtient une suspension renfermant 1 partie d'organes pour 4 parties de diluant. Cette suspension est placée au réfrigérateur pendant 30 minutes. Le surnageant constitue la suspension de virus à $20 \%\left(2 \times 10^{-1}\right)$.

Après 30 minutes de décantation, des dilutions décimales sont préparées, toujours avec le même diluant : de $2 \times 10^{-1}$ à $2 \times 10^{-6}$.

Deux séries de 6 ballons stériles sont préparées.

Les ballons de la première série sont numérotés $A l$ à $A$ 6. Les ballons de la deuxième série sont numérotés $\mathrm{N} l$ à $\mathrm{N} 6$.

Lés ballons $A l$ et $N 1$ reçoivent chacun $35 \mathrm{~cm}^{3}$ de suspension $2 \times 10^{-1}$.

Les ballons $A 2$ et $\mathrm{N} 2$ reçoivent chacun $35 \mathrm{~cm}^{3}$ de suspension $2 \times 10^{-2}$.

Les ballons $A 3$ et $\mathrm{N} 3$ reçoivent chacun $35 \mathrm{~cm}^{2}$ de suspension $2 \times 10^{-3}$.

Les ballons $A 4$ et $\mathrm{N} 4$ reçoivent chacun $35 \mathrm{~cm}^{\prime}$ de suspension $2 \times 10^{-4}$.

Les ballons $A 5$ et $N 5$ reçoivent chacun $35 \mathrm{~cm}^{3}$ de suspension $2 \times 10^{-5}$.

Les ballons $A 6$ et $N 6$ reçoivent chacun $35 \mathrm{~cm}^{2}$ de suspension $2 \times 10^{-6}$.

$A$ chacun des 6 ballons de la série $A$, on ajoute $35 \mathrm{~cm}^{3}$ de sérum contre la peste bovine.

A chacun des 6 ballons de la série $N$, on ajoute $35 \mathrm{~cm}^{2}$ de sérum de bovin réceptif à la peste bovine. Tous les ballons sont alors placés dans des coffres-glacières, pendant 4 heures.

Après ce laps de temps, on effectue les inoculations :

Les chèvres $\mathrm{n}^{08} 1.111,1112,1113,1.114,1.115,1.116$ reçoivent chacune $10 \mathrm{~cm}^{\mathrm{a}}$ du contenu du ballon $\mathrm{N} 1$ (dilution finale du virus $10^{-1}$ ).

Les chèvres nos $1.117,1.118,1.119,1.120,1.121,1.122$ reçoivent chacune $10 \mathrm{~cm}^{3} \mathrm{du}$ contenu du ballon $\mathrm{N} 2$ (dilution finale du virus $10^{-2}$ ).

Les chèvres nos $1.123,1.124,1.125,1.126,1.127,1.128$ reçoivent chacune $10 \mathrm{~cm}^{\mathrm{a}} \mathrm{du}$ contenu du ballon $\mathrm{N} 3$ (dilution finale du virus $10^{-3}$ ).

Les chèvres nos $1.129,1.130,1.131,1.132,1.133,1.134$ reçoivent chacune $10 \mathrm{~cm}^{3}$ du contenu du ballon $\mathrm{N} 4$ (dilution finale du virus $10^{-4}$ ).

Les chèvres $n^{\text {ns }} 1.135,1.136,1.137,1.138,1.139,1.140$ reçoivent chacune $10 \mathrm{~cm}^{\mathrm{a}}$ du contenu du ballon $\mathrm{N} 5$ (dilution finale du virus $10^{-5}$ ).

Les chèvres nos $1.141,1.143,1.144,1.145,1.146,1.147$ reçoivent chacune $10 \mathrm{~cm}^{3}$ du contenu du

ballon $\mathrm{N} 6$ (dilution finale du virus $10^{-6}$ ).

Dans l'autre série :

Les chèvres nos $1.148,1.149,1.150,1.151,1.152,1.153$ reçoivent chacune $10 \mathrm{~cm}^{\mathrm{s}}$ du contenu du

ballon $A 1$ (dilution finale du virus $10^{-1}$ ).

Les chèvres nos $1.154,1.155,1.156,1.157,1.158,1.159$ reçoivent chacune $10 \mathrm{~cm}^{8} \mathrm{du}$ contenu du

ballon $A 2$ (dilution finale du virus $10^{-2}$ ).

Les chèvres nos $1.160,1.161,1.162,1.163,1.164,1.165$ reçoivent chacune $10 \mathrm{~cm}^{8} \mathrm{du}$ contenu du ballon A 3 (dilution finale du virus $10^{-3}$ ).

Les chèvres $\mathrm{n}^{\mathrm{os}} 1.166,1.167,1.168,1.169,1.170,1.172$ reçoivent chacune $10 \mathrm{~cm}^{\mathrm{2}} \mathrm{du}$ contenu du

ballon $\AA 4$ (dilution finale du virus $10^{-4}$ ).

Les chèvres nos $1.174,1.175,1.176,1.177,1.178,1.179$ reçoivent chacune $10 \mathrm{~cm}^{2}$ du contenu du

ballon $A 5$ (dilution finale du virus $10^{-5}$ ).

Les chevres $\mathrm{n}^{\text {os }} 1.181,1.182,1.183,1.184,1.185,1.223$ reçoivent chacune $10 \mathrm{~cm}^{3}$ du contenu du

ballon $\AA 6$ (dilution finale du virus $10^{-6}$ ).

Les animaux inoculés sont laissés à l'attache dans le parc, chaque lot étant isolé des voisins. Les températures sont prises le matin et le soir, les thermomètres étant désinfectés entre chaque prise par immersion dans une solution concentrée de formol.

Un personnel spécial est affecté au lot $A$ (un infirmier et deux manœuvres) et un autre au lot $N$. Les prises de température débutent toujours par le lot 6 et se terminent par le lot 1.

Les observations sont faites pendant 8 jours après l'inoculation.

Les animaux mourants sont autopsiés et l'on recherche la présence des lésions spécifiques (ulcérations bucco-pharyngées, lésions de la valvule iléo-cæcale).

Le quatorzième jour suivant l'inoculation, on procède à l'inoculation de toutes les chèvres survivantes avec une suspension d'organes de chèvres réagissant à la P.P.R. On enregistre ensuite leurs réactions. 


\section{TABLEAU $\mathrm{V}$}

SERIE N

Chèvres inoculées virus P.P.R. + sérum normal bovin

\begin{tabular}{|c|c|c|c|c|}
\hline $\begin{array}{l}\text { DILUTION } \\
\text { virus }\end{array}$ & No & NCUBATION & RÉACTION THERMIOUE & OBSERVATIONS \\
\hline $10^{-1}$ & $\begin{array}{l}1.111 \\
1.112 \\
1.113 \\
1.114 \\
1.115 \\
1.116\end{array}$ & $\begin{array}{l}24 \text { heures } \\
24 \text { heures } \\
24 \text { heures } \\
48 \text { heures } \\
24 \text { heures } \\
24 \text { heures }\end{array}$ & $\begin{array}{l}\text { marquée } \\
\text { marquée } \\
\text { marquée } \\
\text { marquée } \\
\text { très marquée } \\
\text { très marquée }\end{array}$ & $\begin{array}{l}\text { Morte le 15/3. Lésions P.P.R. } \\
\text { Morte le 16/3. Lésions P.P.R. } \\
\text { Vivante le 17/3. Lésions buccales } \\
\text { étendues. } \\
\text { Morte le } 16 / 3 \text {. Lésions pharynx. } \\
\text { Vivante le } 17 / 3 \text {. Lésions buccales. } \\
\text { Morte le } 16 / 3 \text {. Ulcérations pharynx. }\end{array}$ \\
\hline $10^{-2}$ & $\begin{array}{l}1.117 \\
1.118 \\
1.119 \\
1.120 \\
1.121 \\
1.122\end{array}$ & $\begin{array}{l}60 \text { heures } \\
48 \text { heures } \\
48 \text { heures } \\
72 \text { heures } \\
72 \text { heures } \\
66 \text { heures }\end{array}$ & $\begin{array}{l}\text { très marquée } \\
\text { marquée } \\
\text { marquée } \\
\text { peu accentuée } \\
\text { marquée } \\
\text { marquée }\end{array}$ & $\begin{array}{l}\text { Morte le } 16 / 3 \text {. Lésions buccales. } \\
\text { Morte le } 15 / 3 \text {. Lésions P.P.R. } \\
\text { Vivante le } 17 / 3 \text {. Lésions buccales. } \\
\text { Vivante le } 17 / 3 \text {. } \\
\text { Morte le } 16 / 3 \text {. Lésions P.P.R. } \\
\text { Vivante le } 17 / 3 \text {. Lésions buccales. }\end{array}$ \\
\hline $10^{-3}$ & $\begin{array}{l}1.123 \\
1.124 \\
1.125 \\
1.126 \\
1.127 \\
1.128\end{array}$ & $\begin{array}{l}5 \text { jours } \\
48 \text { heures } \\
96 \text { heures } \\
60 \text { heures } \\
96 \text { heures } \\
4 \text { jours }\end{array}$ & $\begin{array}{l}\text { peu accentuée } \\
\text { légère } \\
\text { marquée } \\
\text { très marquée } \\
\text { marquée } \\
\text { marquée }\end{array}$ & $\begin{array}{l}\text { Morte le } 15 / 3 \text {. Lésions 'P.P.R. }+ \\
\text { pneumonie. } \\
\text { Vivante le } 17 / 3 \text {. Lésions buccales. } \\
\text { Morte le } 17 / 3 \text {. Lésions P.P.R. } \\
\text { Vivante le } 17 / 3 \text {. Lésions buccales. } \\
\text { Vivante le } 17 / 3 \text {. Lésions buccaless. }\end{array}$ \\
\hline $10^{-4}$ & $\begin{array}{l}1.129 \\
1.130 \\
1.131 \\
1.132 \\
1.133 \\
1.134\end{array}$ & $\begin{array}{c}4 \text { jours } \\
4 \text { jours } \\
4 \text { jours } \\
72 \text { heures } \\
5 \text { jours }\end{array}$ & $\begin{array}{c}\text { marquée } \\
\text { marquée } \\
\text { peu accentuée } \\
\text { marquée } \\
\text { peu accentuée }\end{array}$ & $\begin{array}{l}\text { Pas de réaction. } \\
\text { Vivante le } 17 / 3 \text {. Lésions buccales. } \\
\text { Vivante le } 17 / 3 \text {. Lésions buccales. } \\
\text { Morte le } 16 / 3 \text {. Lésions P.P.R. } \\
\text { Vivante le } 17 / 3 \text {. Lésions buccales. } \\
\text { Vivante le } 17 / 3 \text {. Lésions buccales. }\end{array}$ \\
\hline $10^{-5}$ & $\begin{array}{l}1.135 \\
1.136 \\
1.137 \\
1.138 \\
1.139 \\
1.140\end{array}$ & $\begin{array}{l}96 \text { heures } \\
96 \text { heures } \\
72 \text { heures } \\
48 \text { heures }\end{array}$ & $\begin{array}{l}\text { tròs marquée } \\
\text { peu marquée } \\
\text { très marquée } \\
\text { très marquée }\end{array}$ & $\begin{array}{l}\text { Vivante le } 17 / 3 \text {. Lésions buccales. } \\
\text { Vivante le } 17 / 3 \text {. Lésions buccales. } \\
\text { Vivante le } 17 / 3 \text {. Lésions buccales. } \\
\text { Vivante le } 17 / 3 \text {. Lésions buccales. } \\
\text { Morte le } 15 / 3 . \text { Misèrephysiologique. } \\
\text { Aucun signe de P.P.R. }\end{array}$ \\
\hline $10^{-6}$ & $\begin{array}{l}1.141 \\
1.143 \\
1.144 \\
1.145 \\
1.146 \\
1.147\end{array}$ & $\begin{array}{l}5 \text { jours } \\
7 \text { jours } \\
5 \text { jours }\end{array}$ & $\begin{array}{l}\text { faible } \\
\text { peu marquée } \\
\text { marquée }\end{array}$ & $\begin{array}{l}\text { Aucun signe de P.P.R. le } 17 / 3 \text {. } \\
\text { Aucun signe de P.P.R. } \\
\text { Aucun signe de P.P.R. } \\
\text { Lésions buccales le } 17 / 3 \text {. } \\
\text { Morte le } 15 / 3 \text {. Pneumonie. } \\
\text { Avortement le 14/3. Vivante le } \\
\quad 17 / 3 \text {. }\end{array}$ \\
\hline
\end{tabular}


TABLEAU VI

SEREE $\mathrm{E}$

Chèvres inoculées virus P.P.R.+séram antibovipestique

\begin{tabular}{|c|c|c|c|c|}
\hline $\begin{array}{l}\text { DLUTION } \\
\text { virus }\end{array}$ & No & INCUBATION & RÉACTION THERMIQUE & OBSERVATIONS \\
\hline $10^{-1}$ & $\begin{array}{l}1.148 \\
1.149 \\
1.150 \\
1.151 \\
1.152 \\
1.153\end{array}$ & $\begin{array}{l}60 \text { heures } \\
24 \text { heures } \\
24 \text { heures } \\
48 \text { heures }\end{array}$ & $\begin{array}{l}\text { moyenne } \\
\text { irrégulière } \\
\text { marquée } \\
\text { marquée }\end{array}$ & $\begin{array}{l}\text { Vivante le } 17 / 3 \text {. Congestion mu- } \\
\text { queuse buccale. } \\
\text { Vivante le } 17 / 3 \text {. Lésions buccales. } \\
\text { Pas de symptômes de P.P.R. le } \\
17 / 3 \text {. } \\
\text { Vivante le } 17 / 3 \text {. } \\
\text { Vivante le } 17 / 3 \text {. } \\
\text { Morte le } 15 / 3 \text {. Pneumonie purulente. }\end{array}$ \\
\hline $10^{-2}$ & $\begin{array}{l}1.154 \\
1.155 \\
1.156 \\
1.157 \\
1.158 \\
1.159\end{array}$ & $\begin{array}{l}48 \text { heures } \\
72 \text { heures }\end{array}$ & $\begin{array}{l}\text { marquée } \\
\text { modérée }\end{array}$ & $\begin{array}{l}\text { Vivante le } 17 / 3 \\
\text { Vivante le } 17 / 3 \\
\text { Vivante le } 17 / 3 \\
\text { Vivante le } 17 / 3 \\
\text { Vivante le } 17 / 3 \\
\text { Vivante le } 17 / 3\end{array}$ \\
\hline $10^{-3}$ & $\begin{array}{l}1.160 \\
1.161 \\
1.162 \\
1.163 \\
1.164 \\
1.165\end{array}$ & & . & $\begin{array}{l}\text { Congestion muqueuse buccale le } \\
17 / 3 \text {. }\end{array}$ \\
\hline $10^{-4}$ & $\begin{array}{l}1.166 \\
1.167 \\
1.168 \\
1.169 \\
1.170 \\
1.172\end{array}$ & 96 heures & marquée & $\begin{array}{l}\text { Vivante le 17/3. Pas de lésions } \\
\text { apparentes. }\end{array}$ \\
\hline $10^{-5}$ & $\begin{array}{l}1.174 \\
1.175 \\
1.176 \\
1.177 \\
1.178 \\
1.179\end{array}$ & & & Morte le 13/3. Pneumonie. \\
\hline $10^{-6}$ & $\begin{array}{l}1.181 \\
1.182 \\
1.183 \\
1.184 \\
1.185 \\
1.223\end{array}$ & & - & $\begin{array}{l}\text { Morte le 16/3. Pneumonie. Absence } \\
\text { de P.P.R. }\end{array}$ \\
\hline
\end{tabular}


TABLEAU VII

Récapitulation

\begin{tabular}{|c|c|c|c|c|}
\hline \multirow{2}{*}{$\begin{array}{l}\text { DILUTION } \\
\cdots\end{array}$} & \multicolumn{2}{|c|}{ SÉRIE N } & \multicolumn{2}{|c|}{ SÉRIE A } \\
\hline & No & Réaction & No & Réaction \\
\hline $10^{-1}$ & $\begin{array}{l}1.111 \\
1.112 \\
1.113 \\
1.114 \\
1.115 \\
1.116\end{array}$ & $\begin{array}{l}+ \\
+ \\
+ \\
+ \\
+ \\
+\end{array}$ & $\begin{array}{r}1.148 \\
1.149 \\
1.150 \\
1.151 \\
1.152 \\
1.153\end{array}$ & $\begin{array}{l}+ \\
+ \\
+ \\
+ \\
+\end{array}$ \\
\hline $10^{-2}$ & $\begin{array}{l}1.117 \\
1.118 \\
1.119 \\
1.120 \\
1.121 \\
1.122\end{array}$ & $\begin{array}{l}+ \\
+ \\
+1 \\
+ \\
+ \\
+\end{array}$ & $\begin{array}{r}1.154 \\
1.155 \\
1.156 \\
1.157 \\
1.158 \\
1.159\end{array}$ & $\begin{array}{l}- \\
- \\
- \\
+ \\
+\end{array}$ \\
\hline $10^{--3}$ & $\begin{array}{l}1.123 \\
1.124 \\
1.125 \\
1.126 \\
1.127 \\
1.128\end{array}$ & $\begin{array}{l}+ \\
- \\
+ \\
+ \\
+ \\
+\end{array}$ & $\begin{array}{l}1.160 \\
1.161 \\
1.162 \\
1.163 \\
1.164 \\
1.165\end{array}$ & $\begin{array}{l}- \\
- \\
- \\
-\end{array}$ \\
\hline $10^{-4}$ & $\begin{array}{l}1.129 \\
1.130 \\
1.131 \\
1.132 \\
1.133 \\
1.134\end{array}$ & $\begin{array}{l}+ \\
+ \\
+ \\
+ \\
+ \\
+\end{array}$ & $\begin{array}{l}1.166 \\
1.167 \\
1.168 \\
1.160 \\
1.170 \\
1.172\end{array}$ & $\begin{array}{rr} & - \\
& - \\
& + \\
- & -\end{array}$ \\
\hline $10^{-5}$ & $\begin{array}{l}1.135 \\
1.136 \\
1.137 \\
1.138 \\
1.139 \\
1.140\end{array}$ & $\begin{array}{l}+ \\
+ \\
+ \\
+ \\
-\end{array}$ & $\begin{array}{l}1.174 \\
1.175 \\
1.176 \\
1.177 \\
1.178 \\
1.179\end{array}$ & $\begin{array}{l}- \\
- \\
- \\
-\end{array}$ \\
\hline $10^{-6}$ & $\begin{array}{l}1.141 \\
1.143 \\
1.144 \\
1.145 \\
1.146 \\
1.147\end{array}$ & $\begin{array}{l}- \\
\overline{-} \\
\overline{+} \\
\overline{+}\end{array}$ & $\begin{array}{l}1.181 \\
1.182 \\
1.183 \\
1.184 \\
1.185 \\
1.223\end{array}$ & $\begin{array}{l}- \\
- \\
- \\
- \\
-\end{array}$ \\
\hline
\end{tabular}

